\title{
La circulación del libro entre España y el virreinato del Perú a fines del siglo XVIII*
}

por

Alejandro Vera ${ }^{1}$

Pontificia Universidad

Católica de Chile
Juan Guillermo Muñoz†

\author{
Luis Hachim² \\ Universidad de \\ Santiago de Chile
}

El presente artículo estudia la circulación del libro entre España y el virreinato peruano a finales del siglo XVIII. A partir de una revisión sistemática, efectuada en el fondo Real Aduana del Archivo General de la Nación del Perú, analiza 48 cargamentos con libros que fueron importados de Cádiz al Callao entre 1779 y 1789, con el fin de ser vendidos en Lima y, en menor medida, en otras ciudades como Santiago de Chile, Cuzco y Guayaquil. El texto está dividido en dos secciones. En la primera, revisa el marco de la historia cultural del libro y la bibliografia existente, para concluir que, sin perjuicio de sus valiosos aportes, esta se ha centrado en los siglos XVI a XVII y no ha examinado los "registros de entrada» del Callao, sino únicamente los «registros de ida» conservados en el Archivo General de Indias. En la segunda sección se presenta una primera evaluación del corpus revisado, que confronta los datos obtenidos con la información ya conocida sobre el tráfico del libro hacia el Perú. Esto permite concluir, entre otras ideas de interés, que la época estudiada se caracteriza por una secularización del material bibliográfico — en gran medida por el incremento de los libros cientificos -; la coexistencia de materiales tradicionales y modernos; la plena compenetración de los impresores españoles con el mercado virreinal - que recibía sus ediciones el mismo año en el que aparecían o poco después-; y la efectiva recepción de los libros importados por parte de los habitantes del virreinato.

Palabras Clave: circulación del libro; España; virreinato del Perú; fines del siglo XVIII.

* Este trabajo ha sido escrito en el marco del proyecto 1150206, financiado por el Fondo Nacional de Desarrollo Científico y Tecnológico de Chile, FONDECYT. Agradecemos al personal del Archivo General de la Nación del Perú, Lima (en adelante AGNP) por las facilidades brindadas durante nuestra investigación. Así mismo, agradecemos la colaboración de Gabriel Rammsy, Francisca Meza y Víctor Estívales, quienes han participado en el proyecto como ayudantes de investigación.

1 averamus@gmail.com, ORCID iD: https://orcid.org/0000-0003-2329-0680.

2 luis.hachim@usach.cl, ORCID iD: https://orcid.org/0000-0001-5294-6066. de uso y distribución Creative Commons Reconocimiento 4.0 Internacional (CC BY 4.0). 
Cómo citar este artículo / Citation: Vera, Alejandro, Muñoz, Juan Guillermo y Hachim, Luis, "La circulación del libro entre España y el virreinato del Perú a fines del siglo XVIII", Revista de Indias, LXXIX/277 (Madrid, 2019): 827-861. https://doi.org/10.3989/revindias.2019.024.

\section{MARCO TEÓRICO Y ESTADO DE LA CUESTIÓN}

El presente trabajo constituye el primer estudio sobre la circulación del libro entre España y el virreinato del Perú a finales del siglo XVIII. El corpus de fuentes a analizar está conformado, principalmente, por 48 cargamentos con libros que ingresaron al Callao entre 1779 y 1789, a partir de los cuales es posible conocer, con relativa precisión, los títulos y tipos de texto que eran importados con mayor frecuencia, así como comparar estos datos con las tendencias que han sido documentadas en la bibliografía previa para el período anterior a 1750 .

Como han señalado acertadamente otros autores, los libros reflejan, como pocos artefactos, el mundo y las personas que los rodean ${ }^{3}$, pues aquello que leían los sujetos del pasado estaba de un modo u otro vinculado con sus «conductas y modos de vida, actitudes y creencias...» ${ }^{4}$. Esta perspectiva, que hace extensiva a los objetos la premisa de que los acontecimientos «tienen rasgos culturales distintivos» y se encuentran «ordenados por la cultura» 5 , implica que un estudio como el presente debe necesariamente situarse en el marco de la historia cultural.

Según Roger Chartier, una historia cultural del libro debería prestar atención especial a su materialidad, puesto que «las obras, los discursos, no existen sino a partir del momento en que se transforman en realidades materiales, en que se inscriben en las páginas de un libro, transmitidos por una voz que lee o relata, o interpretados en el escenario del teatro». En consecuencia, «comprender los principios que gobiernan "el orden del discurso" supone que se descifren en rigor las leyes que fundan los procesos de producción, de comunicación y de recepción de los libros...». Así, y contra la tendencia de la estética de la recepción a concebir el texto como una unidad autónoma o autosuficiente, Chartier nos recuerda que «no hay texto fuera

\footnotetext{
3 Hampe-Martínez, 1993: 212, citando a Laurence Hallewell.

4 González Sánchez, 1996: 8.

5 Burke, 1993: 303.
} 
del soporte que da a leer (o a escuchar), y que por lo tanto no hay comprensión de un escrito, cualquiera sea éste, que no dependa en alguna medida de las formas por medio de las cuales alcanza su lector». De ahí que resulte importante un trabajo como el presente, que estudia el proceso de circulación del libro - $\mathrm{o}$, como diría Chartier, las condiciones materiales que «vehiculizan al texto» ${ }^{6}$ - en un marco histórico y cultural no explorado con anterioridad.

Otro hecho importante que Chartier ha contribuido a evidenciar es la relevancia que los libros tenían para la población no alfabetizada. En los siglos XVI a XVIII la cultura de las mayorías estaba «profundamente penetrada por el libro», que imponía normas pero a la vez hacía posible «usos propios, libres, autónomos» ${ }^{7}$. Como resultado de las diversas formas de lectura en voz alta y la presencia de otros tipos de impreso (imágenes, carteles, folletos), existía una cultura de lo escrito incluso entre quienes no eran capaces de producirlo ni leerlo, ya que el acceso al texto no implicaba, necesariamente, una lectura individual y dependiente de la alfabetización como ocurre en nuestros días ${ }^{8}$. Y aunque Chartier estudia principalmente la Francia del antiguo régimen, sus conclusiones sobre el particular resultan extrapolables al ámbito hispano, por cuanto la lectura en voz alta — además del canto - era una práctica común en la poesía española de la época ${ }^{9}$.

Desde luego, nuestro trabajo no aborda todas las dimensiones que a juicio del autor conformarían una historia cultural del libro, pues deja fuera las diferentes modalidades de lectura y los «gestos de los sujetos lectores», entendidos como la respuesta personal — aunque culturalmente situada - al texto escrito $^{10}$. Sin embargo, al dar a conocer y analizar críticamente los libros importados al virreinato del Perú a fines del siglo XVIII, así como las fuentes utilizadas para su identificación, hace posible que, en un futuro cercano, puedan formularse preguntas relativas a aspectos como los señalados ${ }^{11}$.

Así como los textos de Chartier y otros autores aportan las bases teóricas para un estudio como el presente, la bibliografía previa sobre el tráfico del libro entre España y el Perú es también importante. Reduciendo a una apre-

6 Chartier, 1996: 20, 29. González Sánchez, 2001: 29.

7 Chartier, 1994: 7, 14-26.

8 Chartier, 1995: 10.

9 Frenk, 1987: xix-xx.

10 Chartier, 1995: 148. No obstante, veremos un documento complementario, publicado en el Mercurio Peruano, que ejemplifica cómo fueron recepcionados en Lima algunos de los textos que hemos identificado.

11 Chartier, 1996: 27. 
tada síntesis lo que fácilmente podría ocupar un artículo completo ${ }^{12}$, podemos señalar entre sus principales contribuciones el haber demostrado el estrecho contacto cultural que existía entre el Viejo y el Nuevo Mundo, y la rapidez con que llegaban a América los libros impresos en España y el resto de Europa. Como afirma Hampe-Martínez ${ }^{13}$, los debates eclesiásticos del momento, los géneros literarios más populares y los últimos avances tecnológicos - en una palabra, las ideas de origen europeo - se difundían del otro lado del Atlántico con una velocidad notable, pese a la existencia de medios de comunicación y transporte que hoy podrían parecernos rudimentarios. A modo de ejemplo, Leonard destaca la presencia de un libro editado en 1583 ( $E l$ honesto y agradable entretenimiento de damas y galanes) en un cargamento que fue enviado a Manila a inicios del mismo año ${ }^{14}$; y Lohmann Villena señala que don Tomás Gutiérrez, comerciante de libros residente en el Perú, era a comienzos del siglo XVII «mecenas y favorecedor» del escritor español Juan Pérez de Montalbán ${ }^{15}$.

Lo anterior era posible por la existencia de rutas transoceánicas bien establecidas por las que circulaban no solo los libros, sino muchas otras mercancías, en lo que se conocía como la «carrera de Indias». En los siglos XVI y XVII, ésta se hallaba a cargo de dos grandes flotas que zarpaban anualmente desde Sevilla: una se dirigía al virreinato de Nueva España, que constituía un mercado importante en sí mismo y a la vez un puente para el comercio con Filipinas; la otra se dirigía hacia la región de Tierra Firme, principalmente a los puertos de Portobelo (en la actual Panamá) y Cartagena de Indias (en la actual Colombia); pero la mayor parte de las mercancías que transportaba no paraban allí, ya que eran llevadas a través del istmo a Ciudad de Panamá, para ser reenviadas hacia el Callao, puerto principal de Lima. En ese momento había dos posibilidades: o eran destinadas al uso y consumo de la propia sede virreinal, o bien eran distribuidas hacia otras ciudades del virreinato ${ }^{16}$. Si consideramos que éste abarcaba la mayor parte de Sudamérica, concluiremos que Lima constituía la puerta de entrada al continente para todas las mercancías que llegaban de Europa (hablamos del comercio regular) y en consecuencia tenía una hegemonía tanto desde el punto de vista político como económico.

12 Puede completarse nuestra revisión con la síntesis incluida en Rueda Ramírez, 2005: 23-27.

13 Hampe-Martínez, 1993: 228.

14 Leonard, 2006: 301.

15 Lohmann Villena, 2000: 3.

16 Castillero Calvo, 2000: 356-360. 
Con el tiempo ocurrieron cambios significativos. A finales del siglo XVII el punto de partida se trasladó de Sevilla a Cádiz y más tarde (1717) lo hizo también el Consulado, organismo que se encargaba de administrar la carrera de Indias. A partir de ese momento, Cádiz se convirtió en el puerto español más importante, ya que concentraba la totalidad del comercio oficial con el Nuevo Mundo. Esta hegemonía no se vio disminuida por otros cambios que afectaron al comercio transcontinental en el siglo XVIII: la apertura de la ruta del Cabo de Hornos; la instauración del sistema de navíos de registro (ambos hechos ocurridos en la década de 1740); y el reglamento para el comercio libre promulgado por Carlos III en 1778. Pese a que este último autorizaba a diversos puertos españoles a comerciar directamente con los puertos hispanoamericanos, la magnitud de las franquicias que concedió a Cádiz no hizo más que incrementar su actividad comercial y liderazgo (según estimaciones actuales, luego de promulgarse el reglamento el puerto aumentó sus exportaciones a América en un 400\%). Cádiz constituía también el principal intermediario para el comercio entre el Nuevo Mundo y el resto de Europa, pues albergaba firmas británicas, francesas y alemanas de creciente importancia —aunque en 1762 había 218 firmas españolas por solo 153 extranjeras, éstas absorbían nada menos que el $82 \%$ de las utilidades - ${ }^{17}$.

¿Qué ocurrió con Lima entretanto? Tal como en el caso de Cádiz, su hegemonía tampoco se vio afectada por la apertura del Cabo de Hornos, pues los navíos no estaban autorizados a detenerse en los puertos de la «Mar del Sur»: debían continuar hasta el Callao para efectuar allí el registro de las mercancías y solo posteriormente podían zarpar hacia su destino final. El reglamento para el comercio libre de 1778 tampoco alteró este sistema de manera sustancial, ya que los navíos comerciales siguieron pasando por el Callao antes de recalar en otros puertos del cono sur. Lo que sí afectó a la hegemonía limeña fue el desmembramiento de territorios producido por la creación de los virreinatos de Nueva Granada (1717) y, especialmente, el Río de la Plata (1778). La instauración de este último provocó un fuerte auge de Buenos Aires, que se convirtió en el puerto principal para los territorios que quedaron bajo su jurisdicción. Sin embargo, Lima mantuvo pleno control sobre las ciudades que siguieron perteneciendo al virreinato peruano, algunas cercanas, como Trujillo o Pisco, otras más lejanas y pobladas, como Guayaquil, Quito o los puertos de Chile ${ }^{18}$.

Lo anterior no quiere decir que el reglamento de 1778 careciera de importancia, pues, si bien debió esperar hasta el fin de la guerra con Inglaterra

17 O'Phelan Godoy, 2005: 415-417. Cavieres, 1996: 101-102; 2003: 27-28.

18 Cavieres, 1996: 67, 70-71, 102, 120-121; 2003: 31. 
(1783) para operar en plenitud, contribuyó a incrementar las importaciones desde Europa ${ }^{19}$. Lo confirma un informe redactado en Santiago en 1789, en el que se advierte que las mercaderías del Viejo Mundo estaban inundando las ciudades de Chile con lujos e inclinando «a la gente a lo superfluo» ${ }^{20}$.

Considerando lo anterior, no sorprende que los registros de ida de navíos conservados en el Archivo General de Indias constituyan la fuente que ha sido utilizada con mayor frecuencia para el estudio de la circulación del libro durante el período virreinal. Torre Revello empleó un centenar de ellos en su libro de $1940^{21}$, aunque fue Irving Leonard el primero que los revisó de un modo más sistemático en su serie de estudios sobre el tema compilados en su obra Los libros del conquistador ${ }^{22}$. En una época más reciente, González Sánchez ha utilizado este tipo de fuente en un artículo sobre los registros de $1605^{23}$ y en su monografía Los mundos del libro ${ }^{24}$; y Pedro Rueda ha efectuado un análisis seriado de los registros de ida del siglo XVII en su estudio sobre el libro y la Carrera de Indias ${ }^{25}$.

Como explica este autor, el «registro» era, en estricto sentido, el expediente conformado por la numerosa documentación que debían presentar los barcos que quisieran formar parte de las flotas de Nueva España y Tierra Firme. Sin embargo, el término se aplicaba tanto al expediente completo como a cada una de las anotaciones relativas a la carga que realizaban los propios comerciantes. Éstas podían incluir - aunque no siempre lo hicieran - una lista íntegra de las mercancías a embarcar, ya fuese con vistas al cobro de impuestos o - en el caso específico de los libros - a su revisión por parte de la Inquisición, a objeto de prevenir el envío de libros prohibidos ${ }^{26}$.

Esto último explica que también suelan encontrarse listados de libros en fondos documentales relacionados con el Santo Oficio. Entre los trabajos que han utilizado este tipo de fuente cabe mencionar las extensas monografías de Pedro Guibovich sobre la censura del libro en el Perú ${ }^{27}$ y un capítulo de

19 Lamikiz, 2007: 189-197.

20 Cavieres, 1996: 56.

21 Torre Revello, 1991.

22 Leonard, 2006. Como es sabido, esta obra incluye algunas de sus investigaciones publicadas en las décadas de 1930 y 1940.

23 González Sánchez, 1989: 93-103.

24 Ibidem, 2001.

25 Rueda Ramírez, 2005.

26 Ibidem: 38-50. Otras descripciones del proceso se hallan en Leonard, 2006: 191-206. González Sánchez, 2001: 47-72.

27 Guibovich, 2003; 2014a. Ambas monografías se basan, entre otras fuentes, en documentación del fondo Inquisición del Archivo Histórico Nacional de Madrid. 
González Sánchez sobre su circulación hacia el virreinato en la primera mitad del siglo XVIII'28.

Otras fuentes citadas con frecuencia en la bibliografía previa son los inventarios particulares y los contratos u «obligaciones» comerciales. Los primeros permiten conocer las colecciones de libros que los privados tenían en la época y han sido utilizados, entre otros, por González Sánchez en su trabajo sobre la serie Bienes de difuntos, del Archivo General de Indias ${ }^{29}$, y Teodoro Hampe-Martínez en su estudio sobre las bibliotecas privadas del Perú colonial ${ }^{30}$. Los contratos proporcionan información sobre el comercio del libro en el contexto local - dimensión ausente o escasamente representada en los registros de ida- y han sido aprovechados, entre otros, por Leonard ${ }^{31}$, Guibovich $^{32}$, y Lohmann Villena; este último cita uno de 1609, por el cual un «oficial de libros», llamado Juan de la Puerta, se obliga a venderlos en la plaza mayor de Lima por cuenta del librero Juan de Sarria, a cambio de 180 pesos, casa, comida y ropa limpia ${ }^{33}$.

Un último tipo de fuente que debe mencionarse son los libros que fueron editados en Lima, pues demuestran su condición de principal centro impresor del virreinato y permiten conocer las imprentas que albergaba en la época estudiada $^{34}$. De hecho, no era raro que vecinos de otras ciudades mandasen imprimir en Lima libros de su autoría. Un ejemplo conocido es el del Compendio Historial del Descubrimiento, Conquista, y Guerra del Reyno de Chile (1630) de Melchor Jufré del Águila, vecino de Santiago ${ }^{35}$, pero podemos aportar otro, esta vez desconocido: en marzo de 1784 el dominicano fray José Cruz remitió a su correligionario fray Sebastián Díaz, prior del convento de la Recoleta Dominica de Santiago, 187 ejemplares de una obra que este último había escrito y cuyo título era Noticia general de las cosas del mundo;

28 González Sánchez, 2005. Su fuente principal en este caso es el legajo Contratación 674 del Archivo General de Indias, Sevilla (AGI), que incluye listados de libros revisados por la Inquisición de Sevilla entre 1669 y 1732 aproximadamente.

29 González Sánchez, 1996: 7-47. Esta serie fue también aprovechada por el autor en su monografía posterior ya citada. González Sánchez, 2001.

30 Hampe-Martínez, 1993: 211-233.

31 Leonard, 2006: 287-288.

32 Guibovich, 1984: 85-114. El autor estudia aquí, con mayor profundidad, un documento que ya había revisado Leonard. Otros casos de libreros españoles establecidos en Lima a finales del siglo XVI se estudian en González Sánchez, 2001: 120-151.

33 Lohmann Villena, 2000: 3.

34 A partir de 1770, Medina (1904: xi-xviii) menciona las imprentas de la calle de La Amargura, Juan de Medina, Las Mercedarias, Las Campanas y Bejarano, entre otras.

35 Véase Muñoz, 2011: 10-12. 
Díaz había devuelto dichos ejemplares para que el librero «los corrigiese de cierto defecto de encuadernación»y ahora le eran reenviados en óptimas condiciones $^{36}$. Esta obra se ha conservado hasta nuestros días y, según consta en su portada, fue publicada por la Imprenta Real, que se hallaba en la Calle de Concha ${ }^{37}$. Aunque pudiera cuestionarse la pertinencia de estos datos para un trabajo sobre libros importados desde el Viejo Mundo, veremos que no escapan completamente a nuestro objeto de estudio.

Las fuentes mencionadas no solo han servido a los estudiosos para comprender los mecanismos de envío y las vías por las que circulaban los libros en la época, sino también para identificar los títulos y tipos de texto que eran enviados con mayor frecuencia. En términos generales, predominaban los libros religiosos, si bien la brecha con los textos laicos o seculares tendió a reducirse con el correr de los años: según González Sánchez, los primeros ocupaban cerca del $90 \%$ del total a finales del siglo XVI y un $65 \%$ a comienzos del siglo XVIII ${ }^{38}$. Los estudiosos coinciden sobre este punto, a excepción de Hampe-Martínez, quien afirma que en las bibliotecas privadas había una «extraordinaria predominancia de obras jurídicas»; pero esta aparente contradicción se debe a que la mayor parte de los propietarios estudiados por dicho autor estaba involucrada en el gobierno y las leyes, por lo cual no representaba al tipo de usuario predominante en la época ${ }^{39}$.

En términos más específicos, González Sánchez destaca, a finales del siglo XVI, el predominio de la literatura espiritual y los libros de rezo entre los textos religiosos, y la literatura médica y la gramática entre los textos seculares ${ }^{40}$. Rueda confirma la continuidad de estas tendencias en la centuria siguiente, pero señala un incremento de la literatura de entretenimiento y especialmente las novelas - incluyendo las de caballería - entre las que destacan el Guzmán de Alfarache de Mateo Alemán y el Quijote de Cervantes. En el campo de la poesía, Lope de Vega ocupa un lugar de preferencia con la $A r$ cadia y la Hermosura de Angélica, entre otras. En cambio, la literatura humanística aparece en una proporción inferior a la que podría esperarse ${ }^{41}$. Hampe-Martínez, por su parte, considera a esta última, representada por edi-

36 AGNP, Real Aduana, C 16.696-595. A mediados del mes siguiente, los libros hicieron su ingreso al puerto de Valparaíso. Véase Archivo Nacional Histórico, Santiago de Chile, Contaduría Mayor, 2, ${ }^{\mathrm{a}}$ serie, vol. 2281, fol. 21.

37 Según la descripción realizada por Medina, 1905: 134-135. La portada no lleva año de impresión.

38 González Sánchez, 2001: 75; 1996: 7-47; 2005: 52.

39 Hampe-Martínez, 1993: 211-233.

40 González Sánchez, 1996: 7-47.

41 Rueda Ramírez, 2005: 191-445. 
ciones de los clásicos grecorromanos y gramáticas como la de Nebrija, el tercer tipo más frecuente, después de las obras jurídicas y religiosas, aunque esta diferencia podría estar condicionada por las características ya señaladas de los sujetos que estudia, así como por incluir en su análisis el siglo XVI ${ }^{42}$. Finalmente, González Sánchez apunta un predominio de los libros espirituales (devocionales y ascéticos) a comienzos del siglo XVIII y añade que eran cultivados por todos los sectores sociales, hecho que explica el empleo frecuente de lenguas romances y la «vulgarización de contenidos abstractos y complejos» que los caracteriza. Entre la literatura laica destaca una vez más los nombres de Alemán y Cervantes, pero también los de Lope, Calderón de la Barca y - entre los nacidos en el Nuevo Mundo- Sor Juana Inés de la Cruz y Garcilaso de la Vega. Además, señala una ausencia casi total de relatos de caballerías y otras aventuras fantásticas propias del Renacimiento, hecho que distinguiría a este período del anterior ${ }^{43}$.

De la síntesis previa se desprenden al menos dos vacíos importantes que nuestro trabajo puede contribuir a llenar. Primero, se aprecia un notorio desequilibrio entre la producción dedicada a la época de los Austrias y aquella dedicada a la época borbónica, sobre todo si consideramos las últimas décadas del siglo XVIII y las siguientes, que han sido las menos atendidas. El período 1700-1750 es cubierto solo por la primera de las dos monografías de Guibovich sobre la Inquisición y un capítulo de González Sánchez, ambos ya cita$\operatorname{dos}^{44}$, mientras que el período posterior solo ha sido estudiado por Guibovich, en la segunda de dichas monografías ${ }^{45}$ y en su reciente edición del inventario de libros de Pedro José Chávez de la Rosa (1787) ${ }^{46}$. Por lo tanto no existe, hasta la fecha, trabajo alguno sobre el tráfico del libro hacia el virreinato peruano con posterioridad a $1750^{47}$.

42 Además, y pese a su representación menor, considera importantes los textos de medicina, astronomía e historia natural. Véase Hampe-Martínez, 1993: 211-233.

43 González Sánchez, 2005: 37-72.

44 Guibovich, 2003. González Sánchez, 2005.

45 Guibovich, 2014a.

46 Guibovich, 2014b. Cabe señalar que hemos localizado otra copia de este inventario en una fuente distinta a la utilizada por Guibovich. Véase AGNP, Real Aduana, C 16.761-896, partida 212. En esta fuente se afirma que los libros eran para «los párvulos y escuelas de Arequipa». Además, hemos localizado otra remesa de libros, de menores dimensiones, que fue enviada al obispo desde Cádiz en la fragata La Mexicana y reenviada desde Lima por los hermanos Antonio y José Matías de Elizalde, importantes comerciantes activos a finales del siglo XVIII. Véase AGNP, Real Aduana, C 16.789-1020.

47 El trabajo de Cristina Gómez Álvarez sobre el comercio del libro en el virreinato de Nueva España entre 1750 y 1820 escapa geográficamente a nuestro marco de estudio, pero aporta datos de interés para el mismo, como se verá. Gómez Álvarez, 2011. 
Segundo, si bien los registros de ida conservados en el Archivo General de Indias han sido profusamente utilizados, los registros de entrada del Callao aún están a la espera de una revisión exhaustiva ${ }^{48}$. Estos expedientes comenzaron a producirse sistemáticamente tras la erección de la Real Aduana de Lima (1773), organismo que debía encargarse de registrar los navíos que entraban y salían del puerto, con el objetivo de garantizar el cobro de impuestos $^{49}$. Esto dio origen a numerosos listados de libros - especialmente desde 1779, como se verá- que se conservan en el fondo Real Aduana del Archivo General de la Nación del Perú. Su importancia como fuente resulta aún más clara si se considera que a partir de 1660, aproximadamente, los registros de ida confeccionados en España dejaron de listar en detalle el contenido de los libros embarcados, según han señalado otros autores ${ }^{50}$. Por lo tanto, las fuentes analizadas en nuestro trabajo proporcionan datos que, al parecer, no serían accesibles por otros medios.

En el siguiente apartado, aprovecharemos los registros de entrada del fondo Real Aduana para documentar y analizar el corpus de libros que ingresó al Callao entre 1779 y $1789^{51}$. Nuestra hipótesis principal es que la progresiva disminución en el predominio de los textos religiosos, observada por otros autores entre 1583 y 1750 , se intensificó en los años posteriores, al tiempo que crecía el interés por la lectura no religiosa en sus diversas facetas, a causa de la aún incipiente — pero no despreciable - secularización que se vivió en España y sus colonias. No obstante, el material revisado nos permitirá aportar información complementaria sobre otros aspectos de interés, como la confluencia entre modernidad y tradición, las estrategias editoriales de difusión y la recepción de los textos importados en el medio local.

\section{Cargamentos de libros arribados al Callao (1779-1789)}

La síntesis que presentamos a continuación ha sido elaborada a partir de una base de datos de 4.196 entradas, que hemos extraído de 48 cargamentos con libros que fueron importados a Lima entre 1779 y 1789 (véase el anexo

48 Guibovich cita solo un registro del fondo Real Aduana de Lima, AGNP, concerniente a unos libros que fueron retirados por los hermanos Elizalde, por encargo de Juan Flores del Campo, quien residía en Camaná — véase Guibovich, 2014a: 73, nota 13 (versión electrónica)-.

49 Flores Guzmán, 2010: 314.

50 Así lo expresan González Sánchez, 1996: 13; 2005: 40 y Rueda Ramírez, 2005: 47.

51 Hemos revisado también los registros de salida de Lima, tanto marítimos como terrestres, pero por razones de espacio queda pendiente dar cuenta de la información que contienen. 
1). El año de inicio no es casual, ya que desde 1779 los registros de entrada hacia el Callao comenzaron a incluir con mayor frecuencia el detalle de los libros ingresados ${ }^{52}$. La explicación a este hecho parece hallarse en el reglamento para el comercio libre promulgado el año anterior: si hasta ese momento los derechos de los libros se calculaban de acuerdo al porte del cajón, la nueva normativa estableció que se calcularían según su valor, a razón de un $3 \%$ para los libros españoles y un $7 \%$ para los «extranjeros» ${ }^{53}$; y esto hacía necesario que fuesen registrados individualmente por los cargadores.

Aunque cada entrada de nuestra base de datos corresponde normalmente a un solo título, con frecuencia incluye más de un ejemplar. Por ejemplo, el 26 de noviembre de 1786 se embarcó en Cádiz un cargamento destinado a don Juan de Aguirre, vecino de Lima, que incluía ochenta «Artes de Nebrija, en pasta» ${ }^{54}$, lo que corresponde a una sola entrada. Así, el total de ejemplares que abarca el corpus analizado supera largamente los 76.000, sin que pueda precisarse una cifra exacta por cuanto las fuentes no siempre proporcionan el dato.

Como es común en los registros de aduana, la descripción suele incluir únicamente el autor y el título abreviado de la obra, pero en la mayor parte de los casos (un 70\%) ha sido posible proveer una identificación probable para los libros encontrados, gracias a los numerosos impresos que se encuentran referenciados en línea, digitalizados en Google Libros o mencionados en otras fuentes que citaremos en las páginas que siguen. Cuando la búsqueda ha arrojado varias ediciones para una misma obra, hemos optado por la más cercana al año de envío, ya que, como veremos, parece haber sido frecuente que los libros fuesen remitidos al Callao poco después de haber sido impresos. A partir de esta identificación hipotética hemos sugerido un autor y un título normalizados, así como los datos de edición (lugar, impresor y año de publicación).

Cabe señalar que, aun cuando el corpus revisado constituye una muestra suficientemente representativa, hemos localizado setenta expedientes más en el fondo Real Aduana que incluyen listas de libros y podrían ser de utilidad para otras investigaciones (con este fin los hemos detallado en el anexo 2).

Un aspecto problemático ha sido la clasificación de los textos, que hemos separado en dos grandes categorías (religiosos y seculares), para dividirlos luego en subcategorías (espirituales, científicos, jurídicos, etc.), tomadas en gran medida de los trabajos de González Sánchez y Rueda. Sin embargo, no ha sido posible adscribir todos los libros a un tipo determinado, porque las

52 De los setenta expedientes con listados de libros que hemos incluido en el anexo 2, solo los primeros doce son anteriores a dicho año.

53 Véase al respecto Gómez Álvarez, 2011: 53.

54 AGNP, Real Aduana, C-16 746.826. 
referencias suelen ser poco específicas. Por ejemplo, cuando el original indica «Ramillete de divinas flores» con toda probabilidad se refiere al libro compilado por Bernardo de Sierra a finales del siglo XVII y reeditado en numerosas ocasiones en las centurias siguientes - por tanto, a un texto religioso de carácter misceláneo- ${ }^{55}$. Pero cuando solo indica «Ramillete(s)», sin más datos, podría referir tanto a una antología poética como a una colección de textos sobre diversas materias, religiosas o no ${ }^{56}$; y cuando indica «Ramillete de flores» su identificación tampoco es segura, ya que podría tratarse del libro de Sierra o de alguna de las antologías de poesía secular o religiosa que llevan ese nombre ${ }^{57}$. Para compensar en parte este problema, al indicar los porcentajes para cada conjunto hemos considerado únicamente los libros identificados con relativa seguridad ${ }^{58}$.

Hecha esta salvedad, una de las primeras conclusiones que se desprenden del material revisado es la disminución significativa en la proporción de libros religiosos, que asciende solo al $57 \%{ }^{59}$, cifra muy inferior al $90 \%$ de 1583 y aun al 65 o $70 \%$ de comienzos del siglo XVIII ${ }^{60}$. A todas luces esto refleja la progresiva secularización de España durante dicho siglo, en correspondencia con el gradual asentamiento de las ideas ilustradas. Como explica Manfred Tietz, sin perjuicio de la influencia que mantuvo la Iglesia Católica sobre los distintos campos del saber, fueron varias las voces que comenzaron a exigir una visión laica de los problemas políticos y económicos que afectaban a la

55 Sierra, 1670.

56 El diccionario de la Real Academia Española (en adelante RAE), en su edición de 1780, define el término como una «colección de especies exquisitas y útiles en alguna materia». Poco después, el diccionario de Terreros y Pando (1788) lo define también como «algún libro en que se recogen o juntan algunos pensamientos, o afectos espirituales». También podía referir a una antología de poesía secular como la que se cita más abajo. Hemos tomado las definiciones contenidas en los diccionarios históricos del Nuevo Tesoro Lexicográfico de la Lengua Española publicado por la RAE y disponible en línea en http://ntlle.rae.es/ntlle/SrvltGUIMenuNtlle?cmd=Lema\&sec $=1.1 .0 .0 .0$.

57 Como la que Pedro Flores publicó en Lisboa en 1593 — véase, entre otros, Fernández Montesinos, 1952: 352-378-.

58 Por ejemplo, al indicar los porcentajes para las subcategorías que componen los libros religiosos hemos considerado como total los 3.726 que hemos identificado como tales y no los casos dudosos. El mismo criterio aplicamos en los casos restantes.

59 No parece casual que esta cifra coincida exactamente con el porcentaje de textos religiosos que Gómez Álvarez ha identificado para el tercer cuarto del siglo XVIII en los envíos realizados a Nueva España. Véase Gómez Álvarez, 2011: 92. Por otro lado, la disminución señalada es paralela a la que se observa en París, si bien los porcentajes de impresos religiosos son sensiblemente menores en este caso: 50\% a finales del siglo XVII; $25 \%$ en 1750 ; y solo un 10\% en 1780. Véase Chartier, 1995: 103.

60 González Sánchez, 2001: 75; 2005: 52. 
nación. Ya hacia 1745 se lamentaba el padre Feijoo — bien representado en los cargamentos que hemos revisado ${ }^{61}$ — por el atraso que padecía España en el campo de las «ciencias naturales», al tiempo que abogaba por un desarrollo científico autónomo, independiente de los criterios teológicos ${ }^{62}$. Esto no quiere decir que las ideas ilustradas fuesen desconocidas en España y sus colonias antes de $1700^{63}$, pero no cabe duda de que la Ilustración tuvo un fuerte auge a partir de 1770 , en la medida que se incrementaba el comercio internacional y la difusión de las ideas centroeuropeas ${ }^{64}$.

Entre los libros religiosos, la subcategoría predominante (16\%) está compuesta por «obras espirituales y de devoción», es decir, libros que buscaban orientar al lector en todos los aspectos de la vida cristiana, a objeto de reconducirlo por el camino correcto, marcado por la normativa contrarreformista ${ }^{65}$. Considerando solo a los autores españoles, predomina aquí el gran clásico de la literatura espiritual hispana, fray Luis de Granada, autor infaltable en cualquier cargamento naviero del período colonial ${ }^{66}$. Por lo general figura su colección de obras completas, pero también aparecen títulos más específicos como su Guía de pecadores o su Libro de la oración y meditación, ambos reeditados pocos años antes de su envío a Lima. Le sigue el franciscano Antonio Arbiol (1651-1726), con sus Desengaños místicos —reimpresos en 1772 y 1784- y obras con un perfil más doctrinario, como su Explicación breve de todo el sagrado texto de la doctrina cristiana y La familia regulada, con doctrina de la Sagrada Escritura y Santos Padres de la Iglesia Católica67.

Entre los autores «extranjeros», el más representado — en esta subcategoría y en todo el corpus analizado- es el jesuita francés Jean Croisset (16561738). El texto de su autoría que aparece con mayor frecuencia es el Año cristiano o ejercicios devotos para todos los días del año, que fue publicado en francés en 1712 y posteriormente traducido al castellano por su correligio-

61 Registra 21 apariciones en trece cargamentos. Véase anexo 1, números 1-2, 6, 7-9, $13-15,18,21,33$ y 45.

62 Tietz, 1992a: xii.

63 De hecho, entre los libros que ingresaron al Callao (anexo 1, números 12 y 38) en el período estudiado figura El hombre práctico, de Francisco Gutiérrez de los Ríos y Córdoba (1686), obra que ha sido considerada como un precedente temprano para la Ilustración en España. Véase al respecto Sebold, 2004: 197-200.

64 De hecho, El hombre práctico fue reeditado en 1764 y 1779, lo que demuestra la vigencia de sus premisas en la época que nos ocupa.

65 Rueda Ramírez, 2005: 333-347.

66 Ibidem, 333-334. González Sánchez, 2005: 56; 2001: 85-86.

67 Por la época en que vivió y difundió su obra, Arbiol solo figura en los cargamentos de comienzos del siglo XVIII revisados por González Sánchez, 2005: 55. 
nario José Francisco de Isla ${ }^{68}$. Más que un calendario con «ejercicios», como sugiere el título, esta obra es un extenso compendio de reflexiones espirituales que presentan la vida de los santos como modelo a seguir y discurren sobre las diferentes epístolas y misterios, lo que explica que fuese el libro más famoso en su tipo y alcanzase una amplia difusión en el mundo hispano ${ }^{69}$. Su presencia en los cargamentos revisados da cuenta de la creciente influencia francesa y de una renovación de la literatura de corte espiritual. Sin embargo, los grandes clásicos (Granada, Arbiol y otros) continúan vigentes, lo que pone en evidencia una confluencia entre tradición y modernidad que ya había sido observada por Guibovich en su trabajo sobre la biblioteca del obispo Chávez de la $\operatorname{Rosa}^{70}$. De las referencias contenidas en los registros de aduana se infiere que las versiones importadas debieron ser predominantemente castellanas, pero sabemos gracias al propio Guibovich que también llegó la versión francesa, pues el Santo Oficio de Lima la requisó hacia $1813^{71}$.

Luego de las obras espirituales, los textos religiosos más representados son los libros litúrgicos (11\%). Aquellos que hemos podido identificar ${ }^{72}$ revelan un predominio de ediciones españolas realizadas en Madrid, Segovia y Barcelona (en ese orden) ${ }^{73}$. Su amplia representación dentro del corpus analizado pone en evidencia la importancia de las instituciones religiosas como destinatarias de los libros importados. Un ejemplo elocuente se halla en dos cargamentos con breviarios, diurnos y otros impresos similares que fueron enviados desde Cádiz por Domingo Jordán y Hermanos —agentes del Monasterio de El Escorial - al monje jerónimo Diego de Cisneros — administrador de las «rentas» que el monasterio tenía en Lima ${ }^{74}$ - Cabe recordar que Felipe II había concedido la exclusividad de impresión, distribución y venta de los libros del culto católico a la orden de San Jerónimo ${ }^{75}$. Por tanto, la

68 García Belsunce, 2013: 54-55. El autor fecha en 1753 la primera edición española, pero la más temprana que nosotros hemos localizado fue publicada en 1771 .

69 Lo confirma su presencia en Buenos Aires a comienzos del siglo XIX. Véase García Belsunce, 2013: 55, 158-159.

70 Guibovich, 2014b.

71 Ibidem: 423.

72 El mayor obstáculo aquí ha sido la frecuente imprecisión de las referencias («diurnos», «misales en $4 .{ }^{\circ} »$, etc.).

73 Varios breviarios, diurnos, misales, octavarios, pontificales y rituales se indican como «romanos», pero esto no implica que fuesen impresos en Roma, sino solo que se ajustaban a la liturgia romana.

74 Anexo 1, números 5 y 16. Hay además un tercero, más tardío (1792), que no ha sido incluido en dicho anexo. Véase AGNP, Real Aduana, Real Aduana, C 16.832-1256.

75 Campos (2009: 513, 515) no menciona a Domingo Jordán y Hermanos, pero señala que en la década de 1760 cumplía esta función José Juan Bautista Jordán e Hijo. 
importancia de Segovia en la edición de libros litúrgicos podría deberse a su cercanía con El Escorial.

Otro tipo de texto bien representado en la muestra es el catecismo $(6 \%)^{76}$. El que aparece con mayor frecuencia es el del jesuita Jerónimo (Martínez) de Ripalda (1536-1618), cuyo título es Catecismo y exposición breve de la doctrina cristiana. Aunque la edición original es de 1591, probablemente las versiones embarcadas en Cádiz fuesen las que se imprimieron en Madrid en 1771 y 1783. El número de envíos en los que figura (cuatro) ${ }^{77}$ y la cantidad de ejemplares (cerca de 6.000) evidencia un incremento en su comercialización, ya que Rueda solo registra 309 ejemplares de 1613 a 1649, distribuidos en tres cargamentos ${ }^{78}$. Su éxito se explica en parte por su brevedad y bajo precio: se transportaba por «docenas» y cada ejemplar costaba 5 o 6 reales.

Aparte del catecismo de Ripalda, figura con frecuencia el del francés François-Aimé Pouget (1666-1723), titulado Instrucciones generales en forma de catecismo. Fue publicado originalmente en 1702 y traducido al castellano en 1784 por Francisco Antonio de Escartín y Carrera. Si esta última es la edición que figura en los registros de aduana, como parece, entonces fue enviada a Lima entre 1785 y 1788, es decir, poco después de haber sido impresa ${ }^{79}$.

El último texto de este tipo que hemos hallado con cierta frecuencia es el Catecismo histórico de Claude Fleury (1640-1723). Fue publicado en Francia a finales del siglo XVII y traducido al castellano a partir de 1728 , en varias ocasiones. Las ediciones de 1773, impresas por Antonio de Sancha y Andrés Ortega en Madrid, fueron prohibidas por la Inquisición ${ }^{80}$, pero posteriormente se realizó una en Mallorca (1777), que acaso pudo ser la que arribó a Lima en $1779^{81}$.

Tanto los casos de Pouget y Fleury como el ya citado de Croisset demuestran la influencia que tuvieron los autores franceses en la literatura sacra de finales del siglo XVIII. Esto coincide con los idiomas de los textos importados - si nuestras inferencias sobre los autores y ediciones son correctas-, pues, luego del castellano (72\%) y el latín (22\%), la lengua más representada es el francés $(3 \%)$, seguida muy de lejos por el italiano y el inglés (apenas $0,2 \%$ ).

76 El Diccionario de la RAE (1783) lo define como «El libro en que se contiene la explicación de la doctrina cristiana, y sirve para instruir en sus artículos y misterios».

77 Anexo 1, números 4, 8, 21 y 26.

78 Rueda Ramírez, 2005: 325-326. Como él mismo señala, es muy probable que también correspondan al catecismo de Ripalda otros títulos que aparecen indicados simplemente como «catecismos» o «doctrinas», sin más especificación.

79 Anexo 1, números 7-9, 13-15, 17, 21, 27-28, 36, 38, 43 у 45.

80 Guibovich, 2014a: 372.

81 Simón Díaz, 1982: 119, registra otras ediciones españolas de esta obra. 
Esto parece confirmar que la modernización de España y sus colonias se vio impulsada en gran medida - aunque no exclusivamente- por la traducción de obras francesas, como ya han señalado otros autores ${ }^{82}$.

Entre los textos impresos en Francia que los limeños debieron leer directamente en su lengua, por no haber traducciones castellanas, se halla el Abrégé de l'histoire ecclésiastique de Bonaventure Racine, publicado en Colonia a mediados del siglo XVIII. Esta obra ingresó en el Callao en 1785 y $1786^{83}$, pero al poco tiempo los tomos 10 a 13 fueron prohibidos por la Inquisición ${ }^{84}$, lo que podría explicar su desaparición de los registros navieros posteriores $\mathrm{y}$, de paso, confirmar la afirmación de Guibovich de que el Santo Oficio estaba lejos de ser una institución en decadencia a finales del período colonial ${ }^{85}$.

Sin perjuicio del leve predominio que mantienen los libros religiosos, el hecho más significativo es el aumento de los textos seculares (43\%) y los cambios que éstos presentan con relación a épocas anteriores. Según González Sánchez, en los siglos XVI y XVII predominaban las gramáticas de la lengua castellana y los diccionarios ${ }^{86}$, pero en nuestra muestra lo hacen los libros de ciencia ( $7 \%$ del total y $16 \%$ de la categoría). Por tanto, el incremento de los libros seculares se explica en gran medida por el aumento de la bibliografía científica que consumían los habitantes del mundo hispano, lo que confirma que éste no fue ajeno a la influencia del cientificismo ilustrado.

Entre los textos científicos, se mantiene el predominio de los libros de medicina ya observado en los siglos anteriores ${ }^{87}$. El autor preponderante en este rubro es el médico español Martín Martínez (1684-1734), cuyas obras sobre anatomía fueron publicadas en la primera mitad del siglo XVIII, pero seguían vigentes en la década de 1780. Encontramos en los registros de entrada su Anatomía completa del hombre, su Examen nuevo de cirugía moderna y sus Noches anatómicas o anatomía compendiosa. Es muy posible que la versión de la Anatomía... que recibieron Nicolás Gandarillas en Santiago y Lorenzo Alonso de la Madrid en Lima ${ }^{88}$ fuese la que imprimió Benito Cano en 1788 , en cuyo caso la obra habría sido enviada al virreinato el mismo año de su edición.

\footnotetext{
82 Álvarez Barrientos, 1996: 167-176.

83 AGNP, Real Aduana, C-16 728.754, C-16 746.826 y C-16 746.828.

84 Guibovich, 2014a: 370-371.

${ }^{85}$ Hipótesis que constituye el eje central de su libro ya citado —véase Guibovich, $2014 \mathrm{a}-$

86 González Sánchez, 1996: 31-32.

87 Ibidem: 32.

88 Anexo 1, números 43 y 45.
} 
Otros científicos bien representados en nuestro corpus son el médico suizo Samuel Auguste Tissot (1728-1797) y el naturalista francés George-Louis Leclerc, conde de Buffon (1707-1788). El primero escribió unos Avisos sobre las enfermedades más frecuentes en las personas letradas y «de campo», que fueron publicados en la década de 1760 y traducidos al castellano a partir de 1771. Como en otros casos, pensamos que el Aviso a los literatos y poderosos enviado a finales de 1786 pudo corresponder a la edición impresa en Madrid ese mismo año. En cuanto a Leclerc, figuran en varias ocasiones su Historia natural del hombre y su Historia natural, general y particular. Posiblemente fuesen mayoritariamente ediciones castellanas impresas en las décadas de 1770 o 1780, pero en dos casos es posible afirmar que se trataba de ediciones francesas: el ejemplar indicado como «Juego de la Historia natural de Buffon 2 tomos en $8^{\circ}$ pasta París 1781», que recibió Juan de Aguirre a finales de $1786^{89}$; y el que figura como «Épocas de la naturaleza 2 tomos», tanto por incluirse en un lote de libros «de impresión estranjera» como por no haberse publicado traducciones de esta obra en la época estudiada ${ }^{90}$.

El segundo escalón entre los libros seculares lo ocupan los textos de historia y jurídica (ambos con un 5\% del total y 11\% en su categoría). Entre los primeros figuran decenas de «historias de» naciones o ciudades, incluyendo los libros de viaje, tan frecuentes en el siglo XVIII. El autor más representado es el historiador francés Charles Rollin (1661-1741), con Historia antigua de los egipcios... e Historia de las artes y ciencias, que fueron traducidas al castellano desde 1756. Su caso resulta de especial interés por razones que explicaremos hacia el final de este apartado. Los libros jurídicos exhiben una marcada renovación, ya que escasean textos «clásicos» que abundaban en épocas anteriores, como los de Antonio Gómez y Luis Velásquez de Avendaño $0^{91}$, y predominan en cambio los de autores contemporáneos. El más representado es Francisco Antonio de Elizondo (1743- $i$ ?), jurista de quien poco se sabe, cuya obra Práctica universal forense de los tribunales superiores de España y las Indias fue editada en Madrid en la segunda parte del siglo XVIII. Le siguen el presbítero Manuel Machicado y Rosillo y el licenciado Francis-

89 Anexo 1, número 40. Cabe advertir que la partida original señala en este caso que el cargamento incluye solo «efectos españoles», pero por la indicación queda claro que se trata de una edición parisina y por tanto de un ejemplar «extranjero». Esto confirma que los documentos aduaneros presentan a veces imprecisiones - aunque esto puede decirse de cualquier fuente de época-.

90 Anexo 1, número 29. Leclerc, 1780, vol. 1.

91 Véase sobre ellos Rueda Ramírez, 2005: 368. Gómez es protagonista a comienzos del siglo XVII, ya que aparece en quince memorias o listados. 
co María de Vallarna, cuya obra Additiones legales hispanicae ad Bibliothecam R.P. Fr. Lucii Ferraris figura en cinco cargamentos ${ }^{92}$.

El cuarto lugar entre los libros seculares (4\% del total y $9 \%$ de su categoría) lo ocupan los textos educativos, es decir, cartillas, diccionarios y obras lexicográficas destinadas a la instrucción, particularmente en el campo de la lectoescritura. Antonio de Nebrija (1441-1522) es el autor más representado, especialmente por su gramática latina, conocida en la época como Arte de Nebrija, que figura en ocho cargamentos ${ }^{93}$.

En el quinto lugar aparece la novela (4\% del total y $8 \%$ entre los textos seculares), que se sitúa por encima de los libros de teatro y poesía ${ }^{94}$. El protagonismo de este género resulta de gran interés por cuanto evidencia un auge de la narrativa por sobre la lírica y la dramática, poniendo en evidencia que, en el siglo XVIII, la idea de literatura había trascendido la noción de bellas letras, es decir, aquella producción que asociaba el lenguaje ornado como atributo de belleza y que caracterizaba no solo el significante (palabra), sino también el significado, a través del apego estricto al aparato retórico o la aplicación de estrategias tropológicas (tropos y figuras). La literatura -en el contexto ilustrado - se constituiría como conocimiento y no solo recuperaría las poéticas clásicas, sino que incorporaría el estudio y la reflexión actualizada sobre la experiencia.

Desde el siglo XVII, El Quijote de Cervantes encarnaba el paradigma de la novela moderna europea. No sorprende, pues, que esta obra figure en dieciocho de los cargamentos revisados ${ }^{95}$. Pero también encontramos otras novelas del autor, como Los trabajos de Persiles y Sigismunda y La Galatea.

Mientras el Quijote mantiene el protagonismo de épocas anteriores, el Guzmán de Alfarache de Alemán solo figura ocasionalmente ${ }^{96}$, lo que no se condice con su enorme éxito en el siglo XVII y su presencia aún importante

92 Anexo 1, números 8, 12, 38 y 40-41. Según la Gaceta de Madrid, Madrid, donde fue anunciada la obra, ambos autores estaban activos en la capital española en la época (el segundo era miembro del Colegio de Abogados). Véase Gaceta de Madrid, 38, 1783: 418.

93 Anexo 1, números 13, 15, 20-21, 26-27, 38 y 40. Una síntesis de la trayectoria de esta obra, incluyendo la reforma que le hizo el jesuita Luis de la Cerda a comienzos del siglo XVII, puede verse en Perona, 2010: 44-46. Sobre su llegada al Nuevo Mundo véase González Sánchez, 2001: 100-101.

${ }^{94}$ Los textos teatrales presentan una considerable disminución con relación a épocas anteriores, lo que no deja de llamar la atención si se considera la fascinación que el teatro había despertado en la sociedad colonial y los provechos didácticos que le atribuía la Ilustración. Véase González Sánchez, 2005: 62.

95 Anexo 1, números 2, 6, 8-9, 13, 15, 18, 20, 24, 26-28, 33, 36, 38, 42, 43 у 45.

96 Anexo 1, números 9, 14 y 18. 
a comienzos del XVIII ${ }^{97}$. Este cambio refleja un menor interés por la «picaresca» como género y el «pícaro» como personaje, posiblemente por su escasa correspondencia con los ideales ilustrados.

Destacan además autores como Cristóbal Lozano, con Soledades de la vida $y$ desengaños del mundo... y Giulio Cesare Croce con Historia de la vida, hechos y astucias sutilísimas del rústico Bertoldo, la de Bertoldino su hijo y la de Cacaseno su nieto (Obra de gran diversión y de suma moralidad, donde hallará el sabio mucho que admirar, y el ignorante infinito que aprender).

La importancia de las novelas identificadas queda aún más clara si consideramos no solo sus apariciones, como hemos hecho hasta ahora, sino el número de ejemplares enviados. El Quijote supera la centena y lo mismo ocurre con las novelas de Tomás de Iriarte (1750-1791), autor muy popular en la época, mientras que las Soledades de Lozano, La mujer feliz del Filósofo Incógnito, Las aventuras de Telémaco de François de Salignac y las Novelas de María de Zayas y Sotomayor alcanzan cincuenta ejemplares o más.

Estos datos confirman el poco efecto que tuvieron en el tiempo las disposiciones del siglo XVI que prohibían la distribución de literatura profana en el Nuevo Mundo. Por ejemplo, una real cédula de 1543 había censurado el envío del Amadís «y otros de esta calidad, de mentirosas historias» ya que podían inculcar en los indios «malas costumbres y vicios» ${ }^{98}$. Pero, como se ha señalado, la reiteración de estas normas era un reflejo de su incumplimiento ${ }^{99}$.

Se hace preciso reconocer que la narrativa fue una experiencia común en el Perú de finales del siglo XVIII, conformándose como acción enunciativa transversal en novelas como las que hemos podido documentar, pero también en bitácoras, diarios, informes, relaciones, crónicas, biografías y otras escrituras del período. Recordemos que el concepto de ficción no se reduce a la fantasía (entendida como facultad potencialmente perniciosa), sino que constituye una forma de composición común a distintos géneros escriturales y cuyas evidencias históricas, geográficas, políticas, biográficas y culturales encajan sin violencia con otros modos de tramar y componer textos, habituales en la experiencia de contar. Ya decía Covarrubias que la ficción era una cosa

... compuesta como las fábulas, [...] algunas veces damos nombres de fábulas a las cosas que fueron ciertas y verdaderas, pero en su discurso tienen tanta variedad que parecen cosas no acontecidas, sino compuestas e inventadas de algún gallardo y lozano ingenio. Los que habéis leído las corónicas de las Indias, cosa que

97 Sobre la presencia de ambas novelas en épocas anteriores, véase, entre otros: Rueda Ramírez, 2005: 229-231 y González Sánchez, 2001: 106-107; 2005: 60.

98 Véase Quesada, 1917: 33-77.

99 González Sánchez, 2001: 20-21. Rueda Ramírez, 2005: 34-35. 
pasó ayer, tan cierta y tan sabida, mirad cuantas cosas hay en su descubrimiento y en su conquista, que exceden a cuanto han imaginado las plumas de los vanos mentirosos que han escrito libros ${ }^{100}$.

Al mismo tiempo, la información presentada invita a revisar hipótesis anteriores que presumían un escaso consumo de la novela por parte del público hispano hasta 1790 y un «renacer» del género en los años posteriores ${ }^{101}$.

Aparte de los autores, géneros y títulos más representados, la información contenida en los registros de entrada hace posible reflexionar acerca de su producción. Si nuestras hipótesis respecto a las ediciones enviadas son correctas, Madrid constituía, con diferencia, el principal centro impresor en la España de la época, ya que el $69 \%$ de los libros identificados fue publicado allí. Muy atrás quedan otras ciudades españolas como Barcelona (7\%) y Valencia (4\%), aunque en su conjunto configuren al área mediterránea como la principal alternativa al predominio madrileño.

Entre las ciudades extranjeras la más importante es París (3\%), lo que se condice con la creciente influencia de autores franceses que ya hemos comentado. Le siguen Venecia (poco menos de $3 \%$ ) y Roma $(0,8 \%)$, aunque es posible que esta última se halle subrepresentada en nuestra base de datos, por haber aún muchos libros litúrgicos que no hemos podido identificar.

Finalmente, pese a su escasa representación, cabe señalar que los registros de entrada incluyen libros impresos en Lima ${ }^{102}$. Se trata de obras jurídicas, históricas y religiosas de autores como el peruano Pedro José Bravo de Lagunas (1703-1762) o el español José Antonio Manso de Velasco (1688-1767), virrey del Perú entre 1745 y 1761. Por tanto, algunos libros de origen limeño debieron seguir un trayecto de ida y vuelta como el siguiente: eran enviados a España en grandes cantidades; una vez allí eran puestos a la venta por libreros de Madrid, Sevilla, Cádiz y otras ciudades; y algunos de los compradores los llevaban posteriormente a América en sus equipajes personales o los enviaban a sus cercanos. Esto explicaría que se incluyan predominantemente en envíos particulares: en un caso fueron remitidos al Marqués de Salinas por su hijo, Tomás Fernández de Paredes; y en otro fueron llevados por Pedro Muñoz de Arjona, cuando pasó a Lambayeque como corregidor de la provincia de Saña ${ }^{103}$. La excepción es la Regla consueta o instituciones eclesiásticas

100 Covarrubias Orozco, 2006.

101 Véase Tietz, 1992b: 233-238.

102 Anexo 1, números 6, 14 y 33.

103 Este último dato consta en su expediente de pasajero a Indias, conservado en el AGI, Contratación, 5524, N.1, R.84, disponible en el Portal de Archivos Españoles, http://pares. mcu.es (consultado el 13-04-2017). 
de la Santa Iglesia Cathedral del Cuzco de Juan Manuel de Moscoso y Peralta ${ }^{104}$, que fue enviada a Domingo Zepeda en 1786, con fines comerciales ${ }^{105}$.

El predominio de Madrid coincide con el protagonismo de los impresores madrileños. El más importante, con más de 300 apariciones, es Joaquín Ibarra, originario de Zaragoza, pero establecido en la capital española desde 1742. Le siguen, aunque a considerable distancia, Pedro Marín (189 apariciones) y Antonio de Sancha (188). El primero era primo de Ibarra y en 1770 heredó el negocio de su padre, Antonio Marín, importante tipógrafo de la corte ${ }^{106}$. Sancha era natural de Torija (provincia de Guadalajara) y en 1739 se radicó en Madrid, donde trabajó inicialmente con el impresor Antonio Sanz, para luego fundar su propia librería y taller alrededor de 1755. Más adelante colaboraron con él sus hijos Manuel y Gabriel, el segundo de los cuales se hizo cargo del negocio tras fallecer su padre en $1790^{107}$.

Lo interesante es que todos ellos tenían contactos con Cádiz y el Nuevo Mundo, y esto les permitía situar sus obras en los mercados de ultramar apenas salían de la imprenta. En la Gaceta de México, México D.F., se anunciaban las ediciones de Ibarra y Gabriel de Sancha prácticamente al mismo tiempo que eran publicadas, si no antes ${ }^{108}$. En algunos casos se invitaba a los potenciales interesados a adquirirlas anticipadamente, mediante una suscripción. Por ejemplo, un aviso publicado en abril de 1798 en el Postillón al Correo de Cádiz instaba a los lectores a suscribirse a una nueva edición del Quijote, a cargo de Gabriel de Sancha. El texto, que por su interés amerita una transcripción in extenso, describe en detalle las características del libro, con un marcado énfasis en aspectos visuales:

Nueva subscripción que a la Historia de D. Quijote de la Mancha de Miguel de Cervantes Saavedra, publica D. Gabriel de Sancha, impresa en volúmenes pequeños.

Considerando la variedad de formas y tamaños en que hasta ahora se ha impreso la Historia de D. Quijote de la Mancha, que son en folio, en $4^{\circ}$ mayor, $4^{\circ}$ menor, en $8^{\circ}$ mayor, en $8^{\circ}$ marquilla, en $8^{\circ}$ común, en $8^{\circ}$ menor, y que faltaban otros tamaños todavía menores; a contemplación de algunos aficionados a la lec-

104 Véase su descripción en Medina, 1904: 138.

105 Dado que el registro incluye el avalúo detallado de cada libro con vista al cobro de impuestos.

106 Los datos sobre Ibarra y Marín provienen de Villegas García, 1993: 9-26, 61-63.

107 Véase Sánchez Espinosa, 2014: 217-259. Cabe señalar que Manuel de Sancha y Antonio Marín también se hallan representados en la muestra, aunque en una proporción inferior.

108 Gómez Álvarez, 2011: 86. 
tura de esta inmortal novela, que desean tener el gusto de llevarla cómodamente consigo dentro y fuera de casa, y aun pasearse con ella, se ha resuelto publicar una nueva edición en tamaño pequeño y reducido. Ésta, a excepción de las estampas, será idéntica en todo con la que está acabando de imprimir D. Juan Antonio Pellicer, Bibliotecario de S. M. y Académico de número de la Real Academia de la Historia. Constará de la misma corrección del texto, formal y material, y de las mismas notas que tanto la ilustran, aunque para dejar libres y desembarazadas las planas, no van al pie de ellas, sino al fin de cada tomo. Adornarán esta edición y la amenizarán treinta y dos curiosas viñetas, de asuntos por lo común nuevos, de cuya ejecución se ha encargado D. Luis Paret, Vice-Secretario de la Real Academia de S. Fernando, bien conocido por la delicadeza de sus pinceles, y D. Juan Moreno Tejada, famoso por sus buriles. Llevará asimismo las dos firmas originales de Cervantes, sacadas al vivo de sus respectivos auténticos instrumentos por D. Francisco Javier de Palomares y D. Torquato Torio, y grabadas por el referido Tejada. Precederá una estampa que sirve de frontispicio, y al fin del último tomo se pondrá una nueva carta geográfica o itinerario de los viajes de D. Quijote, y le acompañará una descripción geográfico-histórica. Cuyo mapa y descripción se pondrá igualmente al fin de la impresión en $8^{\circ}$ mayor; aunque en el plan de su descripción no se tuvo presente ni este costoso mapa ni otra nueva estampa que se añade sobre el origen del Guadiana, cueva de Montesinos y lagunas de Ruidera, ni las dos mencionadas firmas originales de Cervantes, ni menos se cargó su valor e importe a los subscriptores, porque el pensamiento y su desempeño ha sido posterior a la publicación de su plan, como se infiere de él mismo, donde no se hace mención de ninguna de estas cuatro láminas. Éstos son los bellos requisitos y las apreciables circunstancias que harían preferible esta nuestra edición en tamaño pequeño a cualquiera otra que careciese de ellas. La cual constará de 8 volúmenes, dividiéndose cada una de las dos partes de que se compone en 4. La vida de Miguel de Cervantes, tan aumentada como ha visto ya el público, se imprimirá en tomo separado; el que subscribiese acudirá a la librería del referido Sancha, donde dejará su nombre, y cuando reciba los dos primeros tomos entregará el importe de ellos, repitiéndose esta misma diligencia en las demás entregas, que constarán también cada una de otros dos tomos, a excepción de la última, que se compondrá de tres, inclusa la vida del autor. Su importe a la rústica será de 10 reales tomo ${ }^{109}$.

El hecho de que este aviso fuese publicado el mismo año en la Gaceta de México ${ }^{110}$, con una diferencia de pocos meses (septiembre), confirma las redes a gran escala que manejaban los impresores madrileños y contribuye a entender su predominio en los cargamentos navieros.

Podría pensarse que los avisos citados son demasiado tardíos y no reflejan lo que ocurría en la década previa, pero algunos libros contenidos en los registros de aduana dan cuenta de una realidad similar. Uno de ellos, escrito por

109 Postillón al Correo de Cádiz, Cádiz, 30, abril de 1798: 117-119.

110 Gaceta de México, IX/9, septiembre de 1798: 70-71. El texto presenta algunas variantes, pero su contenido es esencialmente el mismo. 
el organista español Vicente Adán, se titula Documentos para instrucción de músicos y fue embarcado en Cádiz en septiembre de $1786^{111}$. Dado que la única edición conocida fue impresa por José Otero ese mismo año, este método musical ratifica que algunos libros eran enviados al Perú tan pronto se publicaban, como ya habíamos sugerido.

Las conclusiones anteriores confirman que los libros son «manufacturados por escribas e impresores» casi en mayor medida que «escritos por los autores», por lo cual «no existe ningún texto fuera del soporte material que hace posible la lectura, dado que su significado se construye en un espacio que media entre el discurso del autor y la transformación del mismo en un objeto manejable», como ha apuntado González Sánchez ${ }^{112}$.

En cuanto a los años de envío, la mayor parte de los libros encontrados se concentra en los volúmenes C-16 728.753 a C-16 746.828 del fondo Real Aduana, es decir, en los cargamentos que salieron de Cádiz a finales de 1786. Aun considerando el carácter parcial de la muestra, estos datos parecen explicarse por el impacto que tuvo el reglamento para el comercio libre de 1778. Como ya hemos señalado, su normativa solo fue aplicada en plenitud desde 1783, cuando finalizó la guerra con Inglaterra. A partir de ese año los envíos comerciales hacia el Perú se dispararon hasta alcanzar cifras inusitadas en 1786, que casi triplicaron a las del año anterior. Pero esto llevó a una saturación del mercado local que, al poco tiempo, provocó un brusco descenso en las importaciones ${ }^{113}$. En consecuencia, la circulación del libro refleja en este aspecto los grandes procesos de cambio experimentados por el comercio intercontinental.

Otro dato interesante es la fecha de publicación. Mientras algunas subcategorías, como los libros jurídicos y científicos, muestran una clara renovación, otras evidencian la persistencia de textos muy antiguos: es el caso de los libros religiosos, pero también de la novela, cuyos clásicos son reeditados una y otra vez, sin que esto impida que las producciones más recientes ocupen un lugar importante. La coexistencia del Quijote de Cervantes (1605-1716), Las aventuras de Telémaco de Fénelon (publicadas en torno a 1700) y las Fábulas de Iriarte (1782) da buena cuenta de ello. Esto confirma lo observado en el campo de la historia del libro por Guibovich ${ }^{114}$ y en el de la historia del arte por Ricardo Kusunoki: a finales del siglo XVIII coexistían en Lima distintos «estratos estilísticos»; es decir, se incorporaban las novedades, pero

\footnotetext{
111 Anexo 1, número 15.

112 González Sánchez, 2001: 29. Chartier, 1996: 29-30.

113 Lamikiz, 2007: 191.

114 Véase Guibovich, 2014b.
} 
no por ello se abandonaban los estilos, géneros y autores tradicionales, como si se tratase de «distintos "tiempos" presentes en una misma actualidad colonial» ${ }^{115}$.

Finalmente, quisiéramos aclarar un aspecto que pudiera despertar dudas en el lector. ¿Cómo asegurar que los libros identificados fueron efectivamente leídos por los habitantes del virreinato y no quedaron almacenados en las estanterías de las tiendas comerciales? Si bien el campo de la recepción escapa a nuestro ámbito de estudio, podemos esbozar una respuesta provisoria a partir de las características de las fuentes utilizadas. Mientras que los inventarios de bienes pueden contener libros que se hallaban en la biblioteca del difunto de forma casual, como resultado de un regalo o una herencia ${ }^{116}$, los registros de aduana no presentan este problema, por cuanto el comercio del libro dependía de sujetos especializados en la materia que conocían bien el mercado español y colonial. González Sánchez corrobora esto último al afirmar que «los inventarios de impresores y libreros otorgan una fiabilidad más alta, pues su contenido responde no tanto a los caprichos del azar como a la frialdad aritmética, a los cálculos de la demanda, y de los beneficios...»117; cálculos que se apoyaban en la experiencia previa de los impresores o en los avisos que publicaban en la prensa invitando a los lectores a suscribirse, a objeto de determinar, con un menor margen de error, el número de ejemplares a imprimir. Por tanto, pensamos que una buena parte de los textos importados a Lima entre 1779 y 1789 fue efectivamente leída por los habitantes del virreinato.

Pero, dado que el argumento anterior no es concluyente, pues ninguna serie documental es fiable en un cien por ciento, resulta pertinente volver al caso ya mencionado del historiador Charles Rollin, cuyo nombre figura en un documento complementario de gran interés. Se trata de una "Carta escrita a la Sociedad sobre no ser impropia la música en las representaciones dramáticas", que fue publicada en 1791 en el Mercurio Peruano ${ }^{118}$. Como señala Juan Carlos Estenssoro, el autor, oculto bajo las iniciales «T. J. C. y P.», es el músico y constructor de órganos Toribio José del Campo y Pando, quien recurre a Rollin para sostener que la música es un «presente de Dios» que «añade más viveza, más espíritu y más felicidad para introducir al alma los afectos, y para producirlos con más vehemencia»; que los antiguos romanos la usaban para dar vigor a «los sentimientos del alma»; y que tenían una

\footnotetext{
115 Kusunoki, 2006: 185.

116 González Sánchez, 1996: 11; 2001: 42-43. Chartier, 1994: 38-39; 1995: 140.

117 González Sánchez, 2001: 44.

118 Estenssoro, 1989: 33. Lohmann Villena, 1998: 246.
} 
forma de «declamación compuesta» para el teatro que se escribía en notas musicales ${ }^{119}$. Estenssoro supone que la obra aludida es la Histoire romaine ${ }^{120}$, publicada en 1738, pero en realidad se trata de la Historia de las artes y las ciencias, cuyo tomo primero dedica una extensa reflexión al arte musical y su uso por los «antiguos». Lo confirma el siguiente pasaje, cuya semejanza con las ideas de Campo y Pando no podría ser mayor:

Los antiguos tenían para el teatro una declamación compuesta, y que se escribía con notas, sin que fuese por esto un canto musical; y en este sentido se deben tomar algunas veces en los autores latinos estas palabras: canere, cantus y también carmen, que no siempre significan un canto propriamente [sic] dicho, sino un cierto modo de representar o de leer ${ }^{121}$.

Dado que esta obra ingresó al Callao en cuatro ocasiones, con destino Lima, Arequipa y Santiago de Chile ${ }^{122}$, y que Campo y Pando era un músico nacido y formado en el Perú123, su "Carta...", de 1791 demuestra que los libros importados fueron - al menos en parte- leídos en el virreinato y contribuyeron a configurar el pensamiento local.

\section{CONCLUSIONeS}

Una de las conclusiones más relevantes tiene que ver con la secularización del material bibliográfico que se enviaba de España al virreinato del Perú. Un $57 \%$ de libros religiosos representa una disminución radical con relación al siglo XVI (90\%) e importante con relación a los inicios del siglo XVIII (65$70 \%$ ). Este hecho se relaciona estrechamente con el incremento de los libros científicos, que constituyen la categoría predominante entre los textos seculares, a diferencia de los siglos anteriores, en los que predominaban las gramáticas y los diccionarios. Por tanto, los libros comercializados a finales del siglo XVIII dan cuenta de la decidida introducción en el mundo hispano del cientificismo ilustrado, que comenzaba a transformarse en un campo autónomo, desligado de la teología y la moral religiosa.

119 Campo y Pando, 1791: 134.

120 Estenssoro, 1989: 33.

121 Rollin, 1776: 271-272.

122 Anexo 1, números 4, 12-13 y 43.

123 Nació en Lima en 1743 y era hijo del organero y teórico Gabriel Campo, con quien comenzó a trabajar como ayudante desde los doce años —véase Stevenson, 1999: 979-. 
Entre los textos sacros prevalecen los espirituales y devocionales, seguidos por los libros litúrgicos y los catecismos, mientras que entre los textos seculares predominan - después de los de ciencia- los de historia y jurídica, los «educativos» (cartillas, diccionarios, etc.) y las novelas, en las que se observa una prolongación de la hegemonía del Quijote y un declive en el interés por la picaresca (representada por el Guzmán de Alfarache de Alemán).

Algunas de estas subcategorías exhiben una tendencia a la renovación en cuanto a los autores y textos, mientras otras muestran un marcado tradicionalismo. Como era de esperar, lo primero ocurre con la bibliografía científica, que incluye numerosas obras del siglo XVIII como las de Martínez, Tissot y Leclerc, pero también con los textos jurídicos, que apenas dan espacio a obras clásicas como las de Gómez y Avendaño, para favorecer a autores contemporáneos como Elizondo. En cambio, en el ámbito de la gramática latina continúa predominando el Arte de Nebrija, pese a haber sido escrito a finales del siglo XV. En la mayor parte de los casos, sin embargo, se observa una coexistencia de materiales tradicionales (o clásicos) y contemporáneos (o modernos). Por ejemplo, en las obras espirituales los autores más representados son fray Luis de Granada y el jesuita francés Jean Croisset, el primero del siglo XVI y el segundo del siglo XVIII; entre los catecismos, el más representado sigue siendo el de Ripalda, publicado originalmente en 1591, pero le siguen de cerca los de Pouget y Fleury, que aparecieron hacia 1700 y fueron traducidos al castellano en fechas muy posteriores; y algo similar ocurre en el caso de la novela con Cervantes e Iriarte. Esto parece confirmar un rasgo que ya había sido observado por la historiografía en el Perú tardo-colonial: la coexistencia de «estratos estilísticos» - como los llama Kusunoki- originados en diversos momentos históricos, hecho que pone en evidencia la inadecuación del paradigma evolucionista o progresivo de la historia para estudiar fuentes como las que hemos revisado.

Aparte del contenido y naturaleza de los libros, el presente trabajo proporciona luces respecto a su proceso de producción y distribución. Según los indicios disponibles, Madrid ostentaba un marcado predominio editorial en España, lo que se ve reflejado en la hegemonía de impresores como Joaquín Ibarra, Pedro Marín, Antonio de Sancha y sus descendientes. Todos ellos aprovechaban una amplia red de contactos que iba desde la capital española al Nuevo Mundo - pasando por Cádiz - para difundir sus ediciones. Además, las suscripciones que anunciaban en la prensa - como aquella del Quijote publicada el mismo año (1798) en México y Lima - les permitían estimar las dimensiones de la demanda. De esta forma, sus libros solían ser enviados al Nuevo Mundo el mismo año en el que eran publicados, como ocurrió con el método de música de Vicente Adán, lo que implica que la América colonial 
constituía un mercado importante, que los impresores tenían en cuenta desde el momento mismo en que comenzaban a planear su siguiente edición.

En un ámbito más general, el tráfico del libro refleja algunos de los cambios a gran escala que experimentó el comercio intercontinental. No es casualidad que el mayor número de libros enviado al Callao se concentre en 1786, ya que en ese momento las importaciones de efectos europeos alcanzaron las cotas más altas, a causa del impacto que tuvo el reglamento para el comercio libre. Pero en los años posteriores la cantidad de libros enviados tendió a disminuir, del mismo modo que lo hicieron las demás mercancías europeas, a causa de la saturación del mercado limeño. Esto último podría explicar también que, al poco tiempo (1789), el reino de Chile estuviese «inundado» por efectos europeos: si estos no eran vendidos en Lima, la única opción era exportarlos a otras ciudades del virreinato.

Finalmente, tanto las características de las fuentes analizadas como el caso de la Historia de las artes y las ciencias de Rollin —enviada al Callao de 1779 a 1788 y citada pocos años después por un músico limeño- sugieren que los libros importados fueron efectivamente leídos en el Perú y pasaron así a formar parte de la cultura virreinal.

Anexo 1. Cargamentos con libros analizados EN El PRESENTE trabajo

\begin{tabular}{|c|l|l|l|l|l|l|}
\hline N. & $\begin{array}{c}\text { Fecha de } \\
\text { salida de } \\
\text { España }\end{array}$ & $\begin{array}{c}\text { Fecha de } \\
\text { ingreso al } \\
\text { Callao }\end{array}$ & \multicolumn{1}{|c|}{ Consignatario } & $\begin{array}{l}\text { Ciudad de } \\
\text { destino }\end{array}$ & \multicolumn{1}{|c|}{ Embarcación } & $\begin{array}{c}\text { Fuente en } \\
\text { AGNP, fondo } \\
\text { Real Aduana }\end{array}$ \\
\hline 1 & No precisada & {$[1779]$} & $\begin{array}{l}\text { Manuel Escoriaza; } \\
\text { Antonio de Lama }\end{array}$ & Lima & $\begin{array}{l}\text { San José y las } \\
\text { Ánimas (alias el } \\
\text { Aquiles) }\end{array}$ & C-16 634.294 \\
\hline 2 & No precisada & 1779 & $\begin{array}{l}\text { Juan Lorenzo } \\
\text { Domínguez }\end{array}$ & Lima & Íd. & C-16 634.296 \\
\hline 3 & $26-01-1779$ & No precisada & Manuel Escoriaza & Lima & Íd. & C-16 634.294 \\
\hline 4 & No precisada & $29-08-1779$ & $\begin{array}{l}\text { Francisco Antonio } \\
\text { Martínez }\end{array}$ & Arequipa & San Pablo & C-16 633.291 \\
\hline 5 & No precisada & $04-09-1779$ & Fray Diego Cisneros & Lima & $\begin{array}{l}\text { San José y las } \\
\text { Ánimas (alias el } \\
\text { Aquiles) }\end{array}$ & C-16 634.294 \\
\hline 6 & No precisada & $17-09-1779$ & $\begin{array}{l}\text { Pedro Muñoz de } \\
\text { Arjona }\end{array}$ & $\begin{array}{l}\text { Lambaye- } \\
\text { que }\end{array}$ & $\begin{array}{l}\text { San Pablo } \\
\text { C-16 633.291 }\end{array}$ \\
\hline 7 & No precisada & $22-09-1785$ & $\begin{array}{l}\text { Juan Bautista de } \\
\text { Sarraoa }\end{array}$ & Lima & $\begin{array}{l}\text { Nuestra Señora } \\
\text { de los Dolores } \\
\text { (alias la Ventura) }\end{array}$ & C-16 728.754 \\
\hline
\end{tabular}




\begin{tabular}{|c|c|c|c|c|c|c|}
\hline N. ${ }^{0}$ & $\begin{array}{l}\text { Fecha de } \\
\text { salida de } \\
\text { España }\end{array}$ & $\begin{array}{l}\text { Fecha de } \\
\text { ingreso al } \\
\text { Callao }\end{array}$ & Consignatario & $\begin{array}{c}\text { Ciudad de } \\
\text { destino }\end{array}$ & Embarcación & $\begin{array}{c}\text { Fuente en } \\
\text { AGNP, fondo } \\
\text { Real Aduana }\end{array}$ \\
\hline 8 & No precisada & $30-09-1785$ & $\begin{array}{l}\text { Juan Lorenzo } \\
\text { Domínguez; Juan } \\
\text { Bautista de Sarraoa; } \\
\text { Agustín de } \\
\text { Querejazu }\end{array}$ & Lima & Íd. & C-16 728.754 \\
\hline 9 & No precisada & $04-10-1785$ & Tomás Carmona & Lima & $\begin{array}{l}\text { San Antonio de } \\
\text { Padua }\end{array}$ & C-16 728.753 \\
\hline 10 & No precisada & $05-10-1785$ & $\begin{array}{l}\text { Antonio Barba de } \\
\text { Cabrera }\end{array}$ & Lima & $\begin{array}{l}\text { Nuestra Señora } \\
\text { de los Dolores } \\
\text { (alias la Ventura) }\end{array}$ & C-16 728.753 \\
\hline 11 & No precisada & $15-10-1785$ & Santiago Fariña & Lima & İd. & C-16 728.753 \\
\hline 12 & No precisada & $21-10-1785$ & $\begin{array}{l}\text { Mariano de Ulaortua } \\
\text { [sic]; Antonio Barba } \\
\text { de Cabrera; } \\
\text { Francisco Vásquez } \\
\text { de Ucieda }\end{array}$ & Lima & Íd. & C-16 728.754 \\
\hline 13 & No precisada & $20-12-1785$ & $\begin{array}{l}\text { Esteban Ventura } \\
\text { Mestre }\end{array}$ & $\begin{array}{l}\text { No } \\
\text { precisada }\end{array}$ & $\begin{array}{l}\text { Nuestra Señora } \\
\text { del Rosario, y } \\
\text { Señor San José } \\
\text { (alias el Príncipe } \\
\text { Carlos) }\end{array}$ & C-16 728.753 \\
\hline 14 & No precisada & {$[1786]$} & Domingo Zepeda & Lima & $\begin{array}{l}\text { San José (alias la } \\
\text { Princesa) }\end{array}$ & C-16 745.819 \\
\hline 15 & $27-09-1786$ & No precisada & $\begin{array}{l}\text { Juan Joseph Pérez; } \\
\text { Rafael Francisco } \\
\text { Menéndez } \\
\end{array}$ & Lima & $\begin{array}{l}\text { San Cristóbal } \\
\text { (alias el Dragón) }\end{array}$ & C-16 746.828 \\
\hline 16 & $12-10-1786$ & No precisada & Fray Diego Cisneros & Lima & $\begin{array}{l}\text { San José (alias la } \\
\text { Princesa) }\end{array}$ & C-16 744.818 \\
\hline 17 & $12-10-1786$ & No precisada & $\begin{array}{l}\text { Francisco Antonio } \\
\text { González Laguna }\end{array}$ & Lima & Íd. & C-16 744.818 \\
\hline 18 & $14-10-1786$ & No precisada & $\begin{array}{l}\text { Fray Gabriel } \\
\text { Castellanos }\end{array}$ & Lima & Íd. & C-16 744.818 \\
\hline 19 & $16-10-1786$ & No precisada & Juan de Equino & Lima & Íd. & C-16 744.818 \\
\hline 20 & $19-10-1786$ & No precisada & $\begin{array}{l}\text { Martín Garmendia; } \\
\text { Silvestre de } \\
\text { Amenábar }\end{array}$ & Cuzco & Íd. & C-16 744.818 \\
\hline 21 & $28-10-1786$ & No precisada & $\begin{array}{l}\text { Juan Lorenzo } \\
\text { Domínguez; Agustín } \\
\text { de Querejazu; Juan } \\
\text { Bautista de Sarraoa }\end{array}$ & Lima & Íd. & C-16 745.819 \\
\hline
\end{tabular}




\begin{tabular}{|c|c|c|c|c|c|c|}
\hline N. ${ }^{0}$ & $\begin{array}{l}\text { Fecha de } \\
\text { salida de } \\
\text { España }\end{array}$ & $\begin{array}{c}\text { Fecha de } \\
\text { ingreso al } \\
\text { Callao }\end{array}$ & Consignatario & $\begin{array}{c}\text { Ciudad de } \\
\text { destino }\end{array}$ & Embarcación & $\begin{array}{l}\text { Fuente en } \\
\text { AGNP, fondo } \\
\text { Real Aduana }\end{array}$ \\
\hline 22 & $30-10-1786$ & No precisada & $\begin{array}{l}\text { Francisco de } \\
\text { Miranda }\end{array}$ & Lima & Íd. & C-16 745.819 \\
\hline 23 & $03-11-1786$ & No precisada & $\begin{array}{l}\text { Conde de San Javier } \\
\text { y Casa Laredo }\end{array}$ & Lima & $\begin{array}{l}\text { San Cristóbal } \\
\text { (alias el Dragón) }\end{array}$ & C-16 746.828 \\
\hline 24 & $07-11-1786$ & No precisada & $\begin{array}{l}\text { Juan Pérez; Rafael } \\
\text { Francisco Menéndez }\end{array}$ & Lima & Id. & C-16 746.828 \\
\hline 25 & $09-11-1786$ & No precisada & Domingo Zepeda & Lima & Íd. & C-16 746.828 \\
\hline 26 & $09-11-1786$ & No precisada & $\begin{array}{l}\text { Domingo Zepeda; } \\
\text { Juan Joseph Pérez }\end{array}$ & Lima & Íd. & C-16 746.828 \\
\hline 27 & $09-11-1786$ & No precisada & Ramón Cabeza & Lima & Íd. & C-16 746.828 \\
\hline 28 & $17-11-1786$ & No precisada & $\begin{array}{l}\text { Juan Lorenzo } \\
\text { Domínguez; Agustín } \\
\text { de Querejazu; Juan } \\
\text { Bautista de Sarraoa }\end{array}$ & Lima & İd. & C-16 746.828 \\
\hline 29 & $21-11-1786$ & No precisada & Pedro Falcón & Lima & $\begin{array}{l}\text { Nuestra Señora } \\
\text { del Buen Suceso } \\
\text { (alias San } \\
\text { Francisco de } \\
\text { Asís) }\end{array}$ & C-16 746.823 \\
\hline 30 & $22-11-1786$ & No precisada & $\begin{array}{l}\text { Juan Lorenzo } \\
\text { Domínguez; Agustín } \\
\text { de Querejazu; Juan } \\
\text { Bautista de Sarraoa }\end{array}$ & Lima & $\begin{array}{l}\text { San Cristóbal } \\
\text { (alias el Dragón) }\end{array}$ & C-16 746.828 \\
\hline 31 & $24-11-1786$ & No precisada & $\begin{array}{l}\text { Francisco Martínez } \\
\text { Marañón y Joseph } \\
\text { Errea; Juan de Vega } \\
\text { Bazán }\end{array}$ & $\begin{array}{l}\text { No } \\
\text { precisada }\end{array}$ & $\begin{array}{l}\text { San Juan } \\
\text { Bautista (alias la } \\
\text { Concordia) }\end{array}$ & C-16 746.826 \\
\hline 32 & $24-11-1786$ & No precisada & $\begin{array}{l}\text { Manuel García de } \\
\text { los Reyes }\end{array}$ & $\begin{array}{l}\text { Santiago } \\
\text { de Chile }\end{array}$ & $\begin{array}{l}\text { Nuestra Señora } \\
\text { del Buen Suceso } \\
\text { (alias San } \\
\text { Francisco de } \\
\text { Asís) }\end{array}$ & C-16 746.823 \\
\hline 33 & $24-11-1786$ & No precisada & $\begin{array}{l}\text { Marqués de Salinas } \\
\text { (padre de Thomas } \\
\text { Fernández de } \\
\text { Paredes) }\end{array}$ & Lima & İ. & C-16 746.823 \\
\hline 34 & $24-11-1786$ & No precisada & $\begin{array}{l}\text { Martín Joseph de } \\
\text { Cevallos; Juan } \\
\text { Evangelista Cevallos }\end{array}$ & Lima & Íd. & C-16 746.823 \\
\hline 35 & $24-11-1786$ & No precisada & $\begin{array}{l}\text { Santiago Victores; } \\
\text { Cayetano Fernández } \\
\text { Maldonado }\end{array}$ & Lima & Íd. & C-16 746.823 \\
\hline
\end{tabular}




\begin{tabular}{|c|c|c|c|c|c|c|}
\hline N. ${ }^{0}$ & $\begin{array}{l}\text { Fecha de } \\
\text { salida de } \\
\text { España }\end{array}$ & $\begin{array}{l}\text { Fecha de } \\
\text { ingreso al } \\
\text { Callao }\end{array}$ & Consignatario & $\begin{array}{c}\text { Ciudad de } \\
\text { destino }\end{array}$ & Embarcación & $\begin{array}{c}\text { Fuente en } \\
\text { AGNP, fondo } \\
\text { Real Aduana }\end{array}$ \\
\hline 36 & $25-11-1786$ & No precisada & $\begin{array}{l}\text { Agustín Varela de } \\
\text { Ponte; Bartolomé } \\
\text { Quintela de Ponte; } \\
\text { Juan Reimóndez }\end{array}$ & Lima & Íd. & C-16 746.823 \\
\hline 37 & $25-11-1786$ & No precisada & $\begin{array}{l}\text { Joseph Antonio } \\
\text { González Hevia; } \\
\text { Juan Baptista } \\
\text { Sarraoa; Raymundo } \\
\text { Marres; Pascual } \\
\text { Luegue [sic]; Miguel } \\
\text { Alejandro de Puga }\end{array}$ & Guayaquil & $\begin{array}{l}\text { San Juan } \\
\text { Bautista (alias la } \\
\text { Concordia) }\end{array}$ & C-16 746.826 \\
\hline 38 & $25-11-1786$ & No precisada & Juan de Aguirre & Lima & $\begin{array}{l}\text { Nuestra Señora } \\
\text { del Buen Suceso } \\
\text { (alias San } \\
\text { Francisco de } \\
\text { Asís) }\end{array}$ & C-16 746.823 \\
\hline 39 & $25-11-1786$ & No precisada & $\begin{array}{l}\text { Juan Vives y } \\
\text { Echevarría }\end{array}$ & Lima & Íd. & C-16 746.823 \\
\hline 40 & $26-11-1786$ & No precisada & Juan de Aguirre & Lima & $\begin{array}{l}\text { San Juan } \\
\text { Bautista (alias la } \\
\text { Concordia) }\end{array}$ & C-16 746.826 \\
\hline 41 & $26-11-1786$ & No precisada & $\begin{array}{l}\text { Pedro Joseph de } \\
\text { Zununaga [sic, por } \\
\text { Zuzunaga] }\end{array}$ & Lima & $\begin{array}{l}\text { Nuestra Señora } \\
\text { del Buen Suceso } \\
\text { (alias San } \\
\text { Francisco de } \\
\text { Asís) }\end{array}$ & C-16 746.823 \\
\hline 42 & $28-11-1786$ & No precisada & Tomás Canals & Lima & $\begin{array}{l}\text { San Juan } \\
\text { Bautista (alias la } \\
\text { Concordia) }\end{array}$ & C-16 746.826 \\
\hline 43 & $28-11-1788$ & No precisada & Nicolás Gandarillas & $\begin{array}{l}\text { Santiago } \\
\text { de Chile }\end{array}$ & $\begin{array}{l}\text { Nuestra Señora } \\
\text { de Guadalupe } \\
\text { (alias la } \\
\text { Mexicana) }\end{array}$ & C-16 783.993 \\
\hline 44 & $29-11-1788$ & No precisada & $\begin{array}{l}\text { Joseph Antonio de } \\
\text { León }\end{array}$ & Lima & Íd. & C-16 783.994 \\
\hline 45 & $29-11-1788$ & No precisada & $\begin{array}{l}\text { Lorenzo Alonso de } \\
\text { la Madrid }\end{array}$ & Lima & Íd. & C-16 783.993 \\
\hline 46 & $30-11-1788$ & No precisada & $\begin{array}{l}\text { Cipriano Caballero; } \\
\text { Joseph Manuel } \\
\text { Montalvo }\end{array}$ & Lima & Íd. & C-16 783.994 \\
\hline
\end{tabular}




.../...
\begin{tabular}{|c|c|c|l|l|l|l|}
\hline $\mathbf{N}^{0}$ & $\begin{array}{c}\text { Fecha de } \\
\text { salida de } \\
\text { España }\end{array}$ & $\begin{array}{c}\text { Fecha de } \\
\text { ingreso al } \\
\text { Callao }\end{array}$ & Consignatario & $\begin{array}{c}\text { Ciudad de } \\
\text { destino }\end{array}$ & Embarcación & $\begin{array}{c}\text { Fuente en } \\
\text { AGNP, fondo } \\
\text { Real Aduana }\end{array}$ \\
\hline 47 & $30-11-1788$ & No precisada & $\begin{array}{l}\text { Tadeo Cárcamo; } \\
\text { Diego Larrani [sic, } \\
\text { ¿por Larraín?] }\end{array}$ & $\begin{array}{l}\text { Santiago } \\
\text { de Chile }\end{array}$ & Íd. & C-16 783.994 \\
\hline 48 & $27-01-1789$ & No precisada & $\begin{array}{l}\text { Juan Bautista } \\
\text { Gárate; Silvestre de } \\
\text { Amenábar; José } \\
\text { Hermenegildo de } \\
\text { Isasi }\end{array}$ & Lima & Íd. & C-16 783.994 \\
\hline
\end{tabular}

Anexo 2. Otros Registros de entrada de navíos Procedentes de CÁdiz, CONSERVAdOS EN EL FONDO REAL AdUANA DEL AGNP, QUE INCLUYEN Listados Detallados De libros (NO CONSIDERADOS EN EL ANEXo 1)

C 16.580-33, C 16.581-38, C 16.585-52, C 16.586-56, C 16.604-128, C 16.604-132, C 16.605-133, C 16.605-134, C 16.605-135, C 16.605-137, C 16.606-141, C 16.606-146, C 16.633-289, C 16.761-896, C 16.762-898, C $16.762-899$, C $16.762-900$, C $16.762-902$, C $16.763-903$, C $16.774-953$, C 16.782-988, C 16.782-989, C 16.783-990, C 16.797-1065, C 16.798-1066, C 16.798-1067, C 16.798-1068, C 16.798-1070, C 16.799-1071, C 16.799-1076, C 16.800-1077, C 16.800-1078, C 16.801-1085, C 16.801-1086, C 16.8021089, C 16.802-1090, C 16.803-1092, C 16.803-1093, C 16.803-1095, C 16.804-1097, C C 16.832-1256, C 16.833-1260, C 16.833-1261, C 16.8331262, C 16.833-1263, C 16.833-1264, C 16.841-1306, C 16.876-1465, C 16.877-1468, C 16.877-1470, C 16.887-1539, C 16.939-1852, C 16.939-1853, C 16.939-1855, C 16.976-2085, C 16.976-2087, C 16.976-2089, C 16.9762090, C 16.977-2091, C 16.990-2166, C 16.990-2167, C 16.990-2168, C 16.991-2170, C 16.991-2171, C 16.991-2172, C 16.991-2173, C 16.991-2174, C 16.991-2175, C 16.1008-2292, C 16.1008-2293.

\section{BiBLIOGRAFÍA CITADA}

Álvarez Barrientos, Joaquín, "Imagen francesa y civilización en la novela española del siglo XVIII", Jean-René Aymes (ed.), L'image de la France en Espagne pendant la seconde moitié du XVIII ${ }^{o}$ siècle, París, Presses de la Sorbonne Nouvelle, 1996: 167-176. 
Burke, Peter, "Historia de los acontecimientos y renacimiento de la narración", Peter Burke (ed.), Formas de hacer historia, Madrid, Alianza Editorial, 1993: 287-305.

Campo y Pando, Toribio José del (T. J. C. y P.), "Carta escrita a la Sociedad sobre no ser impropia la música en las representaciones dramáticas", Mercurio Peruano, 83 (Lima, 1791): 131-136.

Campos, Francisco Javier, "El monje jerónimo español fray Diego Cisneros, el Santo Oficio de Lima y el Inquisidor General", Anuario Jurídico Económico Escurialense, 42 (El Escorial, 2009): 513-530.

Castillero Calvo, Alfredo, "Los transportes y las vías de comunicación en Hispanoamérica", Alfredo Castillero Calvo (ed.), Historia general de América Latina, Madrid, UNESCO/TROTTA, 2000, vol. 3: 339-397.

Cavieres, Eduardo, El comercio chileno en la economía mundo colonial, Valparaíso, Ediciones Universitarias de Valparaíso, 1996.

Cavieres, Eduardo, Servir al soberano sin detrimento del vasallo. El comercio hispano colonial y el sector mercantil de Santiago de Chile en el siglo XVIII, Valparaíso, Ediciones Universitarias de Valparaíso, 2003.

Chartier, Roger, Lecturas y lectores en la Francia del Antiguo Régimen, México D. F., Instituto Mora, 1994.

Chartier, Roger, Sociedad y escritura en la Edad Moderna, México D. F., Instituto Mora, 1995.

Chartier, Roger, El orden de los libros. Lectores, autores, bibliotecas en Europa entre los siglos XVI y XVIII, Barcelona, Editorial Gedisa S. A., 1996.

Covarrubias Orozco, Sebastián de, Tesoro de la lengua castellana o española, Madrid, Iberoamericana, 2006 [1611].

Estenssoro, Juan Carlos, Música y sociedad coloniales. Lima 1680-1830, Lima, Colmillo Blanco, 1989.

Fernández Montesinos, José, “Algunas notas sobre el romancero Ramillete de flores”, Nueva Revista de Filología Hispánica, 6/4 (México D. F., 1952): 352-378.

Flores Guzmán, Ramiro Alberto, "Fiscalidad y gastos de gobierno en el Perú borbónico", Carlos Contreras (ed.), Compendio de historia económica del Perú, Tomo 3, Economía del período colonial tardío, Lima, Banco Central de Reserva del Perú/Instituto de Estudios Peruanos, 2010: 295-380.

Frenk, Margit, Corpus de la antigua lírica popular hispánica (siglos XV a XVII), Madrid, Editorial Castalia S. A., 1987.

García Belsunce, César A., Pertenencias extrañas. Libros en Buenos Aires en 1815, Buenos Aires, Academia Nacional de la Historia, 2013.

Gómez Álvarez, Cristina, Navegar con libros. El comercio de libros entre España y Nueva España (1750-1820), Madrid, Trama, 2011. 
González Sánchez, Carlos Alberto, "El libro y la Carrera de Indias: registros de ida de navíos", Archivo Hispalense, 220 (Sevilla, 1989): 93-103.

González Sánchez, Carlos Alberto, "Los libros de los españoles en el virreinato del Perú. Siglos XVI y XVII", Revista de Indias, 56/206 (Sevilla, 1996): 7-47.

González Sánchez, Carlos Alberto, Los mundos del libro. Medios de difusión de la cultura occidental en las Indias de los siglos XVI y XVII, Sevilla, Diputación de Sevilla/Universidad de Sevilla, 2001.

González Sánchez, Carlos Alberto, "Comercio colonial y cultura gráfica europea en el Perú del siglo XVIII", Luis Millones (ed.), Ensayos de historia andina, Lima, Universidad Nacional Mayor de San Marcos, 2005: 37-72.

Guibovich, Pedro, "Libros para ser vendidos en el virreinato del Perú a fines del siglo XVI", Boletín del Instituto Riva-Agüero, 13 (Lima, 1984): 85-114.

Guibovich, Pedro, Censura, libros e inquisición en el Perú colonial, 1570-1754, Sevilla, CSIC/Universidad de Sevilla/Diputación de Sevilla, 2003.

Guibovich, Pedro, Lecturas prohibidas. La censura inquisitorial en el Perú tardio colonial, Lima, Pontificia Universidad Católica del Perú, 2014a.

Guibovich, Pedro, Tradición y modernidad. La biblioteca del obispo Pedro José Chávez de la Rosa, Lima, Pontificia Universidad Católica del Perú, Instituto Riva-Agüero, 2014b.

Gutiérrez de los Ríos y Córdoba, Francisco, El hombre práctico, o discursos varios sobre su conocimiento y enseñanza, Madrid, Miguel Escribano, 1779.

Hampe-Martínez, Teodoro, "The Diffusion of Books and Ideas in Colonial Peru: A Study of Private Libraries in the Sexteenth and Seventeenth Centuries", The Hispanic American Historical Review, 73/2 (Durham, N. C., 1993): 211-233.

Kusunoki, Ricardo, "Matías Maestro, José del Pozo y el arte en Lima a inicios del siglo XIX”, Fronteras de la Historia, 11 (Bogotá, 2006): 183-209.

Lamikiz, Xabier, "El impacto del 'libre comercio' con América: una revisión desde la microhistoria (1778-1796)", Fernando Navarro Antolín (coord.), Orbis incognitvs: avisos y legajos del Nuevo Mundo: homenaje al profesor Luis Navarro García, Huelva, Universidad de Huelva, 2007, vol. 2: 189-197.

Leclerc, George Louis, Les époques de la nature, París, Imprimerie Royale, 1780, vol. 1.

Leonard, Irving A., Los libros del conquistador, México D. F., Fondo de Cultura Económica, 2006 [1949]).

Lohmann Villena, Guillermo, "El público teatral en América durante la época virreinal", Mercedes de los Reyes Peña y Concepción Reverte Bernal (coords.), América y el teatro español del Siglo de Oro (II Congreso Iberoamericano de Teatro), Cádiz, Universidad de Cádiz, 1998: 225-258. 
Lohmann Villena, Guillermo, "Libros, libreros y bibliotecas en la época virreinal", Biblios: Revista electrónica de bibliotecología, archivología y museología, 4 (Brasilia, 2000), disponible en https://dialnet.unirioja.es/servlet/revista?codigo=1849 (publicado originalmente en 1971 en la revista Fénix).

Medina, José Toribio, La imprenta en Lima (1584-1824), Santiago, Casa del autor, 1904, vol. 1.

Medina, José Toribio, La imprenta en Lima (1584-1824), Santiago, Casa del autor, 1905, vol. 3.

Muñoz, Juan Guillermo, Don Melchor Jufré del Águila. Biografía, obra y descendencia, Santiago, sin editorial, 2011.

O’Phelan Godoy, Scarlett, “Una doble inserción. Los irlandeses bajo los Borbones: del puerto de Cádiz al Perú", Scarlett O’Phelan Godoy y Carmen Salazar-Soler (eds.), Passeurs, mediadores culturales y agentes de la primera globalización en el Mundo Ibérico, siglos XVI-XIX, Lima, Pontificia Universidad Católica del Perú, Instituto Riva-Agüero/Instituto Francés de Estudios Andinos, 2005: 411-440.

Perona, José, Antonio de Nebrija, Murcia, Universidad de Murcia, 2010.

Quesada, Vicente, La vida intelectual en la América española, Buenos Aires, La cultura argentina, 1917.

Rollin, Charles, Historia de las artes y ciencias, Madrid, Blas Román, 1776, vol. 1.

Rueda Ramírez, Pedro, Negocio e intercambio cultural: el comercio de libros con América en la Carrera de Indias (siglo XVII), Sevilla, Universidad de Sevilla/ Diputación de Sevilla/CSIC, 2005.

Sánchez Espinosa, Gabriel, “Antonio y Gabriel de Sancha, libreros de la Ilustración, y sus relaciones comerciales con Inglaterra”, Bulletin of Spanish Studies, 91/9-10 (Glasgow, 2014): 217-259.

Sebold, Russell P., Ensayos de meditación y crítica literaria, Salamanca, Ediciones Universidad de Salamanca, 2004.

Sierra, Bernardo de (comp.), Ramillete de divinas flores escogidas en las obras de muchos santos y mejores autores..., Bruselas, Francisco Foppens, 1670.

Simón Díaz, José, Bibliografía de la literatura hispánica, Madrid, CSIC, Instituto Miguel de Cervantes, 1982, tomo XII.

Stevenson, Robert, “Campo (II). 2. Campo y Pando, Toribio José del”, Emilio Casares (ed.), Diccionario de la Música Española e Hispanoamericana, Madrid, SGAE, 1999, vol. 2: 979.

Terreros y Pando, Esteban de, Diccionario castellano con las voces de ciencias y artes y sus correspondientes en las tres lenguas francesa, latina e italiana..., Madrid, Imp. de la viuda de Ibarra, 1788, tomo III. 
Tietz, Manfred, “A modo de prólogo”, Manfred Tietz y Dietrich Briesemeister (eds.), La secularización de la cultura española en el siglo de las luces (actas del congreso de Wolfenbüttel), Wiesbaden, Harrassowitz, 1992a: vii-xv.

Tietz, Manfred, "El proceso de secularización y la problemática de la novela en el siglo XVIII", Manfred Tietz y Dietrich Briesemeister (eds.), La secularización de la cultura española en el siglo de las luces (actas del congreso de Wolfenbüttel), Wiesbaden, Harrassowitz, 1992b: 227-247.

Torre Revello, José, El libro, la imprenta y el periodismo en América durante la dominación española, edición facsimilar de la de 1940, México D. F., UNAM, 1991.

Villegas García, Mariano, J. Ibarra, el grabado y las artes impresoras en el Madrid del siglo XVIII, tesis doctoral, Universidad Complutense de Madrid, 1993.

Fecha de recepción: 12 de mayo de 2017.

Fecha de envío de las modificaciones: 27 de septiembre de 2017.

Fecha de aceptación: 12 de octubre de 2017.

\section{Book circulation between Spain and the Viceroyalty of Peru in the late eighteenth century}

This article studies book circulation between Spain and the Peruvian Viceroyalty at the end of the eighteenth century. Based on a systematic review, carried out in the Real Aduana collection from the Archivo General de la Nación del Perú, it analyses 48 shipments with books imported from Cádiz to Callao between 1779 and 1789, to be sold in Lima and, to a lesser extent, in other cities such as Santiago de Chile, Cuzco and Guayaquil. The text is divided into two sections. The first reviews the framework of the cultural history of the book and preexisting bibliography, to conclude subsequently that, despite its valuable contributions, this has focused on the sixteenth and seventeenth centuries and has not examined the "entry records" of Callao, but only on the "exit records" kept in the Archivo General de Indias. The second section presents a first evaluation of the data gathered from primary sources, comparing these to the information already known about the transit of books to Peru. This allows us to conclude, among other ideas of interest, that the period studied was characterized by: the secularization of bibliographic material, mainly due to an increase in scientific books; the coexistence of traditional and modern works; Spanish printers' total understanding of the viceregal market, which received its editions the same year they appeared or shortly thereafter; and the effective reception of imported books by Viceroyalty inhabitants.

KEY WORDS: book circulation; Spain; Viceroyalty of Peru; late eighteenth century. 